\author{
Giuseppe D'Angelo*, Jlia Pasquali Cerioli** \\ ( ${ }^{*}$ ordinario di Diritto ecclesiastico nell’Università degli Studi di Salerno, \\ Dipartimento di Scienze Giuridiche, Scuola di Giurisprudenza; \\ ** ordinario di Diritto ecclesiastico nell'Università degli Studi di Milano, \\ Dipartimento di Scienze giuridiche "Cesare Beccaria")
}

\title{
L'emergenza e il diritto ecclesiastico: pregi (prospettici) e difetti (potenziali) della dimensione pubblica del fenomeno religioso ${ }^{1}$
}

The pandemic emergency and the ecclesiastical law of the State: advantages (in perspective) and (potential) defects in considering the public dimension of religion.

ABSTRACT: Despite the pandemic emergency, religion is still placed among the elements that contribute to the material and spiritual progress of society. Particularly, the perception of the role of religion is assuming a greater consideration by State institutions and politics as well among the scholars. In this sense, the emergency law is an opportunity to reflect on the public dimension of the religious factor and a good chance to test its merits (in perspective) and (potential) defects.

SOMMARIO: 1. Una collocazione non casuale - 2. Mutazioni, crisi, emergenze. Valori-fini dell'ordinamento e rilettura in continuità del "microsistema costituzionale" del diritto ecclesiastico - 3. Il duplice significato della dimensione pubblica del fenomeno religioso. Ambiguità e contraddizioni nel diritto ecclesiastico pre-pandemico - 4. Le conferme della pandemia. I limiti della libertà religiosa (e gli spunti per la valorizzazione del suo apporto costruttivo) - 5. Il rafforzamento e l'estensione del paradigma collaborativo - 6 . La nuova fase della ripartenza e il binomio collaborazione-sussidiarietà - 7. Riepilogo e rilancio - 8 . Note di discussione: i pregi (prospettici) - 9. (segue) i difetti (potenziali).

\section{1 - Una collocazione non casuale}

\footnotetext{
${ }^{1}$ Il contributo, non sottoposto a valutazione, riproduce il testo, rielaborato e corredato delle note, degli interventi di Giuseppe D'Angelo e Jlia Pasquali Cerioli, rispettivamente relatore e discussant, al convegno su "Valori dell'ordinamento vs esigenze dell'emergenza in una prospettiva multidisciplinare" promosso dal CRC - Centro di Ricerca Coordinato "Studi sulla Giustizia", tenutosi presso 1'Università degli Studi di Milano il 20 e il 21 settembre 2021, ed è destinato alla pubblicazione negli Atti. Giuseppe D'Angelo è autore dei primi sette paragrafi; Jlia Pasquali Cerioli dell'ottavo e del nono.
} 
Desidero anzitutto esprimere il mio più vivo ringraziamento agli organizzatori del convegno e in particolare al prof. Sacchi, nonché, ora anche pubblicamente, al collega e amico prof. Pasquali Cerioli per un invito che mi onora e mi gratifica.

Passo quindi subito al tema del mio intervento.

Riguardato con il distacco che ci si aspetterebbe da quella condizione di abitudine alla convivenza con il coronavirus SARS-CoV-2 in cui dovremmo ormai trovarci un po' tutti, l'impatto dell'emergenza pandemica sul diritto ecclesiastico italiano risulta, in termini di riflessione scientifica, meno sconvolgente di quanto possa apparire a prima vista.

Non si vuole certo, in questo modo, sminuire l'impatto della pandemia sulla concretezza delle condizioni di vita in cui ci siamo ritrovati all'improvviso. È fuor di dubbio che esso sia stato, che sia, devastante.

Ciò che invece intendo dire è che nell'incontro/scontro con le esigenze dell'emergenza, il diritto ecclesiastico sembra confermare - sia pure a un più elevato livello di problematicità e con ben altra incidenza pratica - una linea di tendenza non nuova. O quantomeno non vede spostare di molto i termini essenziali della relazione dialettica lungo la quale esso è andato sviluppandosi più di recente. E, d'altra parte, non nuova - neppure per il diritto ecclesiastico - è la sottoposizione alla pressione deformante che deriva dall'incessante riproporsi del trinomio mutazioni-crisi-emergenze ${ }^{2}$, tratto caratterizzante, ormai ordinario, di questo mondo globalizzato ${ }^{3}$.

Più precisamente, trovo che, riguardato nella prospettiva del diritto ecclesiastico, il tema generale del rapporto tra valori dell'ordinamento ed esigenze dell'emergenza rimandi alla difficile conciliazione tra due modi logicamente distinti ma concretamente interconnessi di guardare alla relazione tra ordinamento giuridico (e quindi valori-fini da esso perseguiti) e interessi religiosi, in cui questi ultimi possono rilevare, rispettivamente, quali istanze di libertà da proteggere e promuovere o

2 Per una sua particolare declinazione (in cui il riferimento è a "globalizzazione, secolarizzazione e immigrazione"), M.C. FOLLIERO, Post-democrazia europea e principio di cooperazione Unione Europea-Religioni, in Stato, Chiese e pluralismo confessionale, Rivista telematica (https:/ / www.statoechiese.it), settembre 2010, p. 1.

3 Sul convergere, "per medesime e omologanti modalità", di emergenza pandemica e globalizzazione, verso il "paradosso di fondo" che caratterizza l'epoca contemporanea, $\mathbf{S}$. BERLINGÒ, Dialogo interculturale e minoranze religiose in Europa al tempo del Covid-19. L'apporto degli ecclesiasticisti, in Stato, Chiese e pluralismo confessionale, cit., n. 39 del 2018, p. 184. 
come pretese di colonizzazione della sfera della politica (o quantomeno di condizionamento delle decisioni che ivi maturano) alle quali opporsi e dalle quali mantenersi il più possibile indenni ${ }^{4}$. È una duplicità di caratterizzazione che, come ci proponiamo di dimostrare in questo contributo, trova ampio riscontro nella più recente riscoperta della dimensione pubblica del fenomeno religioso e che spiega ambiguità e contraddizioni dei correlati processi di relativizzazione della tradizionale specialità normativa del diritto ecclesiastico.

Dare conto di questi processi evolutivi e delle criticità che vi sono sottese vale evidentemente a mettere a fuoco il ruolo di interlocuzione che il fattore religioso è chiamato a giocare nello svolgersi della tensione dialettica tra valori-fini dell'ordinamento ed esigenze dell'emergenza e in particolare nel delicato passaggio dalla fase del contenimento del contagio a quella della ripartenza economica e sociale.

Direi a questo proposito che il posto riservato alla prospettiva del diritto ecclesiastico nella scaletta del Convegno - tra il diritto amministrativo e il diritto tributario, due dei poli di maggiore attrazione verso il diritto comune - costituisca qualcosa di più del riconoscimento di una larga affinità disciplinare.

\section{2 - Mutazioni, crisi, emergenze. Valori-fini dell'ordinamento e rilettura in continuità del "microsistema costituzionale" del diritto ecclesiastico}

Le riflessioni che seguono sono quindi intese, fondamentalmente, a ricercare nella vicenda dell'emergenza pandemica le ragioni di una continuità evolutiva, dall'andamento non sempre lineare, contraddistinta da nodi irrisolti con i quali occorrerà ancora continuare a confrontarsi. È un modo, se si vuole, di guardare al futuro della relazione tra ordinamento giuridico e interessi religiosi superando la logica difensiva e statica del limite e della compressione e valorizzando diversamente la visione costruttiva e dinamica della compartecipazione solidale all'inveramento delle coordinate di trasformazione sociale nella continuità assiologica che sono delineate dalla Costituzione repubblicana. Nello specifico della tematizzazione di questo convegno, ciò equivale a

\footnotetext{
4 Sulla duplice caratterizzazione della religione, rispettivamente, quale libertà e quale potere, A. VITALE, Corso di diritto ecclesiastico. Ordinamento giuridico e interessi religiosi, Giuffrè, Milano, 2005, p. 1-2.
} 
chiedersi, prospettivamente, se e in che modo il fattore religioso possa legittimamente contribuire a sostanziare la risposta giuridica alle esigenze dell'emergenza, senza indebolire ma anzi rafforzando la tenuta dei valorifini dell'ordinamento.

$\mathrm{Al}$ riguardo, giova anzitutto rimarcare come sia ormai fuor di dubbio che il fattore religioso partecipi a pieno titolo al farsi ordinamentale. Gli interessi, individuali e collettivi, che fanno capo al fenomeno religioso concorrono infatti al pieno sviluppo della persona umana (art. 3, secondo comma, Cost.) e al progresso materiale e spirituale della società (art. 4, secondo comma, Cost.). Ciò doverosamente - diremmo anzi inevitabilmente - nel contesto di una visione aperta e pluralista della relazione che si instaura tra istituzioni pubbliche, formazioni sociali e individuo ${ }^{5}$.

Sotto questo profilo, si può dire che i principi peculiari che concorrono a delineare il così detto microsistema costituzionale del diritto ecclesiastico ${ }^{6}$ assolvano al compito di riaffermare la cogenza di quei valorifini, coniugandone la portata precettiva con la specificità dell'elemento religioso ovverosia con la originaria pertinenza di quest'ultimo a un ordine esplicitamente riconosciuto come distinto da quello dello Stato ${ }^{7} \mathrm{ma}$ anche con la varietà e la eterogeneità dei soggetti, dei fini e degli interessi che si rifanno alla religione e che l'ordinamento a sua volta considera come meritevoli di tutela.

L'impegno della Repubblica alla salvaguardia del valore della persona umana e quindi alla tutela promozionale dei diritti e delle libertà

\footnotetext{
${ }^{5}$ Di qui la sottolineatura del "ruolo attuale dell'ecclesiasticista", che «è quello del perito specializzato nelle tecniche di funzionamento di quei particolari strumenti giuridici, anche di natura squisitamente metodologica o procedurale come il principio di legalità e il principio di laicità, attraverso i quali sistemi profani garantiscono al proprio interno la circolazione democratica di valori sostenuti da sistemi "non-profani", più o meno propriamente giuridici»: S. DOMIANELLO, Il pensiero di Maria Cristina Folliero nell'ambito degli studi di Diritto Ecclesiastico e Canonico, in Rigore e curiosità. Scritti in memoria di Maria Cristina Folliero. Cerimonia di consegna dei volumi, a cura di G. FAUCEGLIA, G. D'ANGELO, in Stato, Chiese e pluralismo confessionale, cit., n. 39 del 2018, p. 20.

${ }^{6}$ G. CASUSCELLI, Il diritto ecclesiastico "per principi", in Nozioni di Diritto ecclesiastico, a cura di G. CASUSCELLI, 5 a ed., Giappichelli, Torino, 2015, p. 47, ove si sottolinea che gli elementi normativi che quel sistema contraddistinguono "consentono di evincere, con l'interpretazione sistematica, ulteriori regole e di convergere nella configurazione unitaria di principi quale quello di laicità".

7 Cfr. J. PASQUALI CERIOLI, L'indipendenza dello Stato e delle confessioni religiose. Contributo allo studio del principio di distinzione degli ordini nell'ordinamento italiano, Giuffrè, Milano, 2006.
} 
costituzionali - ivi compresa la libertà religiosa - sostanzia così quella condizione di "non indifferenza dello Stato dinanzi alle religioni" ma di "garanzia dello Stato per la salvaguardia della libertà di religione, in regime di pluralismo confessionale e culturale" 8 che, com'è noto, costituisce la cifra distintiva del principio supremo di laicità ${ }^{9}$ e che, di recente, è stata ribadita (e, in certo modo, chiarita) nella sua portata espansiva e dinamica ${ }^{10}$. Letti in questa connotazione unitaria, quegli stessi principi vanno quindi a comporsi dialetticamente nell'ordinario quadro della legalità costituzionale complessiva, alimentando una relazione, fisiologicamente mutevole, che nel corso del tempo conosce diversi gradi di intensità e che non può non risultare condizionata dal ruolo che la religione concretamente riveste nella società e nella considerazione effettiva dell'ordinamento giuridico ${ }^{11}$. In questo senso, il diritto ecclesiastico non costituisce certo una realtà a sé stante ma si inserisce pienamente nel contesto delle dinamiche di trasformazione che coinvolgono, dall'interno e dall'esterno, l'ordinamento giuridico generale. Condizionandole e, a sua volta, venendone condizionato ${ }^{12}$.

Nella concretezza dell'esperienza politico-istituzionale e giuridica, può quindi accadere che il diritto ecclesiastico traduca secondo modalità e orientamenti specifici e differenziati questa sua doverosa tensione verso la comune piattaforma assiologica ordinamentale. Tanto perché sotto la veste dell'apparente univoco riferimento al fenomeno religioso si nasconde una pluralità di esperienze (individuali, collettive, istituzionali), di forme di manifestazione (ovverosia di attività) e di soggetti (associazioni, enti, confessioni) che la Costituzione stessa mostra di non voler mortificare ma

${ }^{8}$ Così la ben nota Corte Cost., n. 203/1989, par. 4 del Considerato in diritto.

${ }_{9}$ Cfr. S. DOMIANELLO, Sulla laicità nella Costituzione, Giuffrè, Milano, 1999.

10 Di "dinamismo della laicità" parla (richiamando P. FARAGUNA, Ai confini della Costituzione. Principi supremi e identità costituzionale, Franco Angeli, Milano, 2015, p. 88 ss.), J. PASQUALI CERIOLI, (Non)conclusioni: tre questioni su minoranze e laicità positiva negli attuali anni Venti, in Stato, Chiese e pluralismo confessionale, cit., n. 13 del 2021, p. 184, che sottolinea altresì, "in via generale, le caratteristiche di vitalità dei canoni al vertice della gerarchia (proprio in quanto) materiale delle fonti".

11 Ovverosia "dall'atteggiamento di chiusura o, viceversa, di disponibilità che, nei diversi stadi della storia della Repubblica, il diritto pubblico dello Stato assume nei confronti del fenomeno religioso individuale, o di quello collettivo, o di entrambi": M.C. FOLLIERO, Diritto ecclesiastico. Elementi. Principi non scritti Principi scritti Regole. Quaderno 1, I principi non scritti, Giappichelli, Torino, 2007, p. 10.

12 M.C. FOLLIERO, Diritto ecclesiastico, cit., in particolare p. 24 s. nonché, con specifico riferimento all'integrazione del sottosistema delle norme del diritto ecclesiastico nell'alveo della legalità costituzionale multilivello, p. 99 s. 
anzi di volere proteggere e promuovere e che in effetti può restituire di volta in volta risposte peculiari quanto alla composizione tra i poli della libertà e dell'uguaglianza.

In particolare, la centralità - nel contesto dei principi generali di tutela dei diritti inviolabili dell'uomo (art. 2 Cost.) e di eguaglianza formale e sostanziale (art. 3 Cost.) - del riconoscimento della libertà religiosa individuale e del suo esercizio, anche in forma associata (art. 19 Cost.), si pone in linea di continuità con l'esplicita valorizzazione del fine collettivo di religione e di culto (art. 20 Cost.) e con la tutela dei soggetti che tale fine perseguono e si accompagna persuasivamente al peculiare statuto giuridico riconosciuto alla Chiesa cattolica (art. 7 Cost.) e alle confessioni religiose (art. 8 Cost.) nonché alla previsione di un peculiare obbligo di disciplina negoziata delle relazioni che esse intrattengono con lo Stato (il così detto principio di bilateralità necessaria o pattizia).

Il concreto combinarsi di queste coordinate di principio dà luogo a esiti diversificati e sempre in divenire, che dipendono dal mutare dei contesti e dei rapporti di forza che si stabiliscono all'interno della fenomenologia religiosa e nei rapporti tra questa e le istituzioni pubbliche, e che (beninteso, nei limiti del consentito!) possono anche apparire, in una particolare fase, in parziale disallineamento rispetto all'andamento complessivo della legalità costituzionale.

Sappiamo d'altra parte come anche i valori-fini ordinamentali non costituiscano realtà statiche ma siano, all'opposto, soggetti a un continuo processo di attuazione e attualizzazione, che opera a più livelli istituzionali e che a sua volta trova corrispondenza nel carattere circolare e perennemente in divenire dello stesso fenomeno giuridico ${ }^{13}$.

Il fattore religioso e la disciplina giuridica che ne considera fini e interessi sono parte attiva di questa incessante dinamica ${ }^{14}$. Se quindi lo

13 Per una più diffusa analisi del rapporto tra diritto ecclesiastico e dinamiche di attuazione/attualizzazione costituzionale, mi sia consentito rinviare, anche per gli ulteriori richiami bibliografici, a G. D'ANGELO, Prospettive evolutive del diritto ecclesiastico e dinamica della legalità costituzionale tra questioni di principio e riforme "di settore", in Diritto e religioni, n. 2/2018, p. 50 s.

$14 \mathrm{Ne}$ risulta ribadita la connotazione (non chiusa e assimilazionista ma) doverosamente aperta e inclusiva del principio di laicità ovvero la sua "attitudine a intersecare l'evoluzione continua e adattiva dell'esperienza giuridica, oggi più che mai dinamica, aperta e pluralisticamente orientata": S. BERLINGÒ, Libertà di religione e laicità nella comunità politica: dalla "laicità all'italiana" alla "laicità europea"?, in S. BERLINGÒ, G. CASUSCELLI, Diritto ecclesiastico italiano. I fondamenti. Legge e religione nell'ordinamento e nella società d'oggi, Giappichelli, Torino, 2020, p. 210, ove si sottolinea come tale attitudine risulterebbe pregiudicata "da una proposizione e una impostazione rigida del principio 
stesso fattore religioso (si adatta a e) interagisce costruttivamente con i processi di realizzazione dei valori-fini dell'ordinamento, in un rapporto di mutuo condizionamento, il diritto ecclesiastico e i suoi principi di sistema non ne sono indenni. Anche quando appaiono formalmente immutati, essi sono destinati a riadattare dinamicamente il proprio significato generale e le proprie proiezioni operative, considerate singolarmente e nelle reciproche interazioni.

Mutazioni, crisi, emergenze costituiscono quindi anche per il diritto ecclesiastico un interessante banco di prova della tenuta dei propri principi fondanti (in rapporto ai nuovi equilibri operativi che di volta in volta si vengono a creare al proprio interno) e un'occasione per contribuire all'attuazione costituzionale, coniugando al meglio innovazione e continuità. E, sotto questo profilo, anche per il diritto ecclesiastico il problema che si pone consiste nell'impedire che il riadattamento imposto dall'emergenza possa condurre a esiti insostenibili nella prospettiva della tenuta dei valori-fini ordinamentali, cosa che è sempre possibile sol che si (ri)consideri il carattere ambivalente del fattore religioso ovverosia il suo costante oscillare tra i poli della libertà e del potere.

Ciò, per l'appunto, ben prima che l'emergenza acquisisse le sembianze della tragedia planetaria.

\section{3 - Il duplice significato della dimensione pubblica del fattore religioso. Ambiguità e contraddizioni nel diritto ecclesiastico pre-pandemico}

In effetti, al momento della comparsa del coronavirus (e del conseguente affermarsi delle esigenze di contenimento della pandemia), il diritto ecclesiastico si trova coinvolto dagli stessi fattori di trasformazione che investono gli altri settori dell'ordinamento. Essi anzi contribuiscono ad alimentare le inquietudini che, per così dire costitutivamente, lo caratterizzano in conseguenza della peculiarità del suo oggetto di disciplina giuridica e di analisi scientifica ${ }^{15}$ : globalizzazione, immigrazione, crisi di sovranità e delle tradizionali forme di manifestazione della democrazia liberale, progressiva evaporazione dei

di laicità, sotto forma di modello predeterminato, o definito astrattamente una volta per tutte".

15 Se ne può apprezzare un attendibile quadro d'insieme confrontando i contributi presenti in AA. VV., Vivere la transizione. La fine del monopolio delle scienze ecclesiasticistiche e la difficoltà di gestire le nuove dimensioni del fenomeno religioso, in Stato, Chiese e pluralismo confessionale, cit., n. 7 del 2017. 
confini pubblico-privato rappresentano alcuni degli elementi che travolgono strumenti e contenuti (e con essi le categorie consolidate di interpretazione) della disciplina del fenomeno religioso, suggerendo di conseguenza un profondo ripensamento dell'approccio tradizionale ${ }^{16} \mathrm{e}$ spingendo verso una rimodulazione dei principi di sistema che a quel rapporto soprassiedono.

Tali fattori e i processi di trasformazione che derivano dal loro complesso combinarsi trovano sintetico ma efficace riscontro interpretativo nella presa di coscienza della ineludibile dimensione pubblica del fattore religioso. Si tratta di un riconoscimento che non certifica una novità assoluta ma anzi equivale a registrare il verificarsi delle condizioni che consentono al fenomeno religioso di esprimere potenzialità a esso intrinseche, lungo uno sviluppo evolutivo che a sua volta non è estraneo agli obiettivi di progresso "materiale e spirituale" fatti propri dalla Costituzione repubblicana.

In realtà, di per sé, la locuzione è destinata a indicare una pluralità di fenomeni, o meglio più punti di vista di un fenomeno sostanzialmente unitario. In particolare, essa può essere intesa in un (almeno) duplice senso.

Da un primo punto di vista, la sottolineatura della dimensione pubblica del fenomeno religioso intende richiamare, di quest'ultimo, il carattere estensivo e trasversale. In questo caso, cioè, la locuzione fa riferimento al fatto che la religione non si limita necessariamente a governare la relazione tra l'individuo e la divinità (o, se si preferisce, il mondo della trascendenza) ma può alimentare un sistema di regole inteso a conformare il comportamento complessivo del fedele, orientandolo nelle comuni relazioni sociali e quindi anche in riferimento ad ambiti materiali che sembrerebbero invece estranei alla sfera religiosa. Ciò anche in maniera implicita, in virtù dei nessi e delle interconnessioni che la religione stabilisce, per così dire costitutivamente, con la cultura e le tradizioni culturali ${ }^{17}$.

16 Si può dire che queste mutazioni di contesto abbiano reso vieppiù evidente il limite di fondo della pretesa neutralizzazione del fattore religioso e cioè svelato la sostanziale impraticabilità del confinamento del religioso nell'ambito del giuridicamente irrilevante o comunque l'illusorietà di una netta e immutabile demarcazione/separazione degli ordini del religioso e del secolare: M. RICCA, Pantheon. Agenda della laicità interculturale, Torri del Vento, Palermo, 2012.

17 "La compenetrazione tra religione e cultura dipende dai processi storici. In ogni angolo del mondo, in qualsiasi universo immaginario, la religione ha operato nel tempo come agenzia antropologica e di produzione di senso. Le visioni del mondo coestensive a ogni cornice culturale sono cresciute e si sono scolpite anche attraverso il lavorio 
Si può quindi dire che la connotazione pubblica del fenomeno religioso segni il superamento della penalizzante condizione di confinamento nello stretto ambito della sfera intima individuale in cui esso si è trovato lungamente costretto ${ }^{18}$. Ciò significa che la religione cessa di essere considerata come fatto meramente privato e vede di conseguenza moltiplicarsi le proprie proiezioni e le corrispondenti istanze di tutela nell'ordine civile ${ }^{19}$, proponendosi in tal modo come fattore di trasformazione sociale e ponendo nuove sfide in termini di coerenza e coesione ordinamentale. In questa prospettiva, il riconoscimento della dimensione pubblica del fattore religioso certifica il carattere generativo e relazionale di quest'ultimo ovvero la sua piena inclusione nel circuito democratico-pluralista di rilevazione e definizione degli interessi giuridicamente rilevanti ${ }^{20}$.

L'osservazione ci conduce all'ulteriore modo di intendere la dimensione pubblica del fenomeno religioso, sul quale merita soffermarsi in questa sede. Esso costituisce in realtà uno sviluppo del precedente, con cui si mantiene in stretto contatto ma al quale aggiunge ulteriori profili di criticità ${ }^{21}$.

dell'immaginazione religiosa. La fede e le sue categorie di senso hanno agito come una corrente di fondo nella formazione dei saperi e degli abiti culturali, e si sono mimetizzate con essi, sino a rendersi in parte invisibili", sicché "[s]olo quando si demistificasse il mito della laicità integrale, dell'esclusiva razionalità del discorso pubblico, si potrebbe promuovere un effettivo processo di critica della religione e del suo capitale culturale sedimentato nella mentalità comune. In breve, la religione nascosta tra le pieghe dei saperi culturali va sviscerata e guardata in faccia [...]": M. RICCA, Pantheon, cit., (testuali, rispettivamente a p. 11 e p. 18) e, almeno, ID., Oltre Babele. Codici per una democrazia interculturale, Dedalo edizioni, Bari, 2008, in particolare p. s. 177 s.

${ }_{18} \mathrm{Su}$ tali dinamiche, M. RICCA, Pantheon, cit., p. 119 s. nonché, con particolare riferimento alle ricadute su significato e portata della libertà di coscienza, p. $136 \mathrm{~s}$.

19 A. FUCCILLO, L'incidenza professionale del diritto ecclesiastico, in Stato, Chiese e pluralismo confessionale, cit., ottobre 2009, in particolare p. 4-5; ID., Diritto religioni culture. Il fattore religioso nell'esperienza contemporanea, Giappichelli, Torino, 2019, p. 79 s.;

${ }^{20}$ Cfr. M. RICCA, Pantheon, cit., p. 126 s.

21 Di qui l'opportunità di evitare confusioni e fraintendimenti autorevolmente segnalata da G. DALLA TORRE, Considerazioni sull'attuale problematica in materia di libertà religiosa, in Stato, Chiese e pluralismo confessionale, cit., luglio 2014, che in particolare si sofferma sulla necessità di distinguere correttamente tra sfera pubblica ("quella della società civile» in cui «tutte le identità debbono poter entrare; tutte le credenze debbono poter essere presenti; tutte le convinzioni debbono poter essere espresse", atteso che «[1]a loro compressione nel "privato" significherebbe volontà di oscuramento e di eclisse forzosa") e sfera politica ("che è il regno del confronto, del compromesso, dell'acquisizione dei consensi attraverso argomentazioni di carattere puramente 
Qui il riferimento alla dimensione pubblica del fenomeno religioso indica la propensione di quest'ultimo a permeare di sé non soltanto le relazioni che il fedele intesse con la società entro cui vive e opera ma quest'ultima nella sua interezza. Rileva cioè il fatto che la religione si ponga in larga parte quale ideologia totalizzante, fondata su propri valorifini, e in quanto tale volta a conformare l'intera collettività, pretendendo di rendere vincolante per tutti ciò che invece dovrebbe vincolare unicamente il fedele (e, beninteso, a patto che quest'ultimo intenda mantenere intatto il proprio legame religioso).

Del relativo compito sono investiti a vario titolo tutti i soggetti che aderiscono a un determinato credo religioso (i fedeli, per l'appunto) ma è chiaro che esso compete prioritariamente alla comunità religiosa nel suo complesso e, nello specifico, alla struttura organizzativa che, per avventura, ne abbia la rappresentanza unitaria. Possiamo in effetti dire che queste pretese di conformazione e/o trasformazione hanno tante più possibilità di successo quanto più è elevata la capacità di interlocuzione della comunità religiosa e/o dei suoi enti rappresentativi, come testimoniata, a sua volta, dal suo grado di istituzionalizzazione e dalla qualità delle relazioni che essa intrattiene con le istituzioni pubbliche. $\mathrm{E}$ ciò - è il caso di aggiungere - sembra mantenere un suo fondamento anche in un contesto come quello attuale, caratterizzato da una situazione di spiccata fluidità e frammentazione delle appartenenze religiose ${ }^{22}$.

Sta di fatto che, assunta in questa ulteriore sfaccettatura, la dimensione pubblica del fenomeno religioso valorizza in special modo il momento collettivo-istituzionale dell'esperienza di fede. Sono in particolare le comunità e le istituzioni religiose più radicate e influenti ad avvalersi delle possibilità connesse al riconoscimento di questa (solo apparentemente nuova) dimensione, assumendo un ruolo qualificato di interlocuzione (ovvero di collaborazione) con le istituzioni pubbliche per l'assunzione (e l'attuazione) delle decisioni di interesse comune (ovvero generale) ma con potenziali ricadute negative in termini di salvaguardia dei diritti e delle libertà individuali 23 .

razionale, della volontà dei più che alla fine, in democrazia, si impone su quella dei meno. Quella sfera nelle quali sono le istituzioni della polis, che in una società pluralistica non possono che essere ispirate nel loro agire a criteri di imparzialità»).

22 Come si avrà modo di vedere nel prosieguo, infatti, la stessa crisi di rappresentatività delle istituzioni religiose più consolidate convive con la loro spiccata propensione a interagire, non senza successo, con le autorità pubbliche.

23 Per questo riguardo restano tuttora valide le osservazioni di M.C. FOLLIERO, Diritto ecclesiastico, cit., p. 174. 
Sotto questo profilo, si può dire che il duplice verso della dimensione pubblica del fenomeno religioso corrisponda grosso modo al duplice modo di porsi, rispettivamente individuale e collettivoistituzionale, dell'esperienza religiosa. Il che, peraltro, spiega come riprendendo un tema di fondo ben presente ai cultori del diritto ecclesiastico - esse possano entrare in rotta di collisione tra loro ${ }^{24}$.

Peraltro, è il caso di ribadire come entrambe le versioni della dimensione pubblica del fenomeno religioso intersechino e mettano a frutto prospettive di sviluppo che sono ben presenti all'orizzonte costituzionale, laddove salvaguardia e tutela della persona umana in un contesto di solidarietà e pluralismo sono elevati a fini-valori dell'ordinamento. In effetti, quest'ultimo non può certo mostrarsi indifferente nei confronti della dimensione pubblica del fattore religioso proprio perché, ad argomentare diversamente, esso verrebbe meno ai propri fondamenti assiologici e tradirebbe il suo fondamentale talento democratico-pluralista.

Tuttavia, la messa in valore di queste potenzialità innovatrici della Carta non è esente da ambiguità e contraddizioni. In particolare, va segnalato come proprio la presa in carico di questa dimensione pubblica e il correlativo ampliarsi ${ }^{25}$ del raggio di azione della libertà religiosa portino

${ }^{24}$ In altri termini, si può dire che il tema della dimensione pubblica del fenomeno religioso attualizzi un ben noto profilo di criticità interna al concetto giuridico di libertà religiosa, movimentando il già difficile equilibrio tra le dimensioni, rispettivamente, individuale e collettivo-istituzionale dell'esperienza di fede.

${ }^{25}$ Favorito dalle trasformazioni che investono tanto la relazione tra individuo e società che quella che quest'ultima intrattiene con le istituzioni pubbliche. In estrema sintesi si può infatti osservare, quanto al primo aspetto - e cioè alla relazione tra individuo e società - come proprio l'emergenza pandemica abbia dimostrato l'interconnessione delle scelte personali ovvero delle conseguenze degli atti e dei comportamenti che a esse rispondono e la loro comune dipendenza dalle dinamiche di contesto (nonché, problematicamente, l'estrema permeabilità della sfera personale e finanche di quella intima della coscienza individuale) e, di qui, da un lato, l'improponibilità di una concezione della libertà calibrata esclusivamente sul perseguimento dell'interesse egoistico (risiedendo essenzialmente in ciò la "tremendissima lezione del Covid-19": M. RECALCATI, La nuova fratellanza, in La Repubblica, 24 maggio 2020) e, dall'altro, la necessità di contestualizzare e ricomporre continuamente le sue scansioni operative in un quadro di riferimento unitario doverosamente ispirato a responsabilità e solidarietà (si veda ad esempio I. MASSA PINTO, La tremendissima lezione del Covid-19 (anche) ai giuristi, in Questione giustizia (www.questionegiustizia.it), 18 marzo 2020, che in particolare stigmatizza "il dilagare di un'altra malattia, questa assai diffusa tra i giuristi del nostro tempo, che avanza argomenti formalistici in una situazione nella quale una popolazione, che fino all'altro giorno mostrava comportamenti generali per lo più anarcoidi, sembra mostrare ora timidi segni di solidarietà".). Parallelamente - veniamo invece al rapporto 
fisiologicamente quest'ultima a confrontarsi, su di un piano paritario, con diritti e interessi, anche di rilievo costituzionale, a essa contrastanti ma altrettanto meritevoli di tutela. In questo senso, alla presa d'atto della trasversalità dell'esperienza religiosa non può che corrispondere la sua più compiuta contestualizzazione costituzionale ovverosia la necessità di ricercare nella composizione bilanciata degli interessi interferiti ragioni e limiti del suo riconoscimento da parte dell'ordinamento giuridico.

In questo senso, può dirsi che all'estensione, quantitativa e qualitativa, delle istanze di tutela positiva della libertà religiosa corrisponda, almeno apparentemente, una sua maggiore vulnerabilità se non proprio una sorta di degradazione quanto a forme e strumenti di salvaguardia. È cioè, in buona sostanza, proprio nell'implementarsi delle proiezioni civili della libertà religiosa (o, se si preferisce, del riconoscimento della dimensione pubblica del fattore religioso) che risiede la ragione primaria e più incisiva della progressiva perdita del carattere di specialità delle norme dedicate nonché, nello specifico, di quella tendenza all'attrazione della stessa libertà religiosa verso l'applicazione dei canoni di ragionevolezza e proporzionalità che - come si è osservato autorevolmente 26 - costituisce lascito della pandemia tra i più significativi e meritevoli di approfondimento scientifico.

Quanto al diritto ecclesiastico pre-pandemico, il saldo non appare sempre positivo, né in termini di eguale tutela della libertà religiosa né sotto il profilo della salvaguardia della specificità degli interessi religiosi ${ }^{27}$.

tra istituzioni pubbliche e forme organizzative della così detta società civile - è il concetto stesso di spazio pubblico-istituzionale, quale luogo metaforico entro il quale autorità a ciò deputate (e quindi definite esse stesse pubbliche) esercitano poteri orientati alla concreta cura di interessi riferibili alla collettività e perciò caratterizzati da una particolare efficacia nei confronti dei soggetti sociali (definiti privati) e in cui ancora prima le stesse autorità maturano e assumono, in assoluta autonomia, le decisioni relative alla individuazione e alla selezione di quegli interessi (G. CASUSCELLI, I simboli religiosi, in Nozioni, cit., p. 47), a modificarsi sensibilmente, aprendosi in maniera sempre più significativa alla presenza dei privati e, quindi, all'apporto costruttivo delle religioni. Che quindi sono poste in condizione di affiancare (se non proprio di sostituire) le istituzioni pubbliche nello svolgimento delle attività così dette di interesse generale (art. 118, quarto comma, Cost.).

26 G. CASUSCELLI, Gli "effetti secondari" (ma non troppo) della pandemia sul diritto ecclesiastico italiano e le sue fonti, in Stato, Chiese e pluralismo confessionale, cit., n. 8 del 2021, p. 2.

27 E qui è forse opportuno precisare che se la specialità delle norme di diritto ecclesiastico è talora divenuta sinonimo di privilegio e quindi di eccezionalità, essa dovrebbe essere invece intesa, correttamente, come sinonimo di specializzazione: è la peculiarità dei bisogni, degli interessi e dei diritti che si rifanno alla religione (e quindi 
Ad esempio, si ha che l'assorbimento della libertà religiosa nell'alveo delle libertà economiche e la conseguente sottoposizione dell'agire economico-sociale dei soggetti religiosi alla disciplina europea in materia di tutela della concorrenza e del libero mercato producano importanti effetti perequativi all'interno della fenomenologia religiosa ma comportino nel contempo un non secondario svilimento della peculiarità delle ragioni religiose dell'impegno nelle attività così dette di interesse generale $^{28}$. In altri casi - e con il non secondario avallo di esigenze emergenziali di diversa aggettivazione, ovvero securitarie e/o economicofinanziarie ${ }^{29}$ - l'estensione del raggio di azione della libertà religiosa (ovverosia l'ampiezza delle sue proiezioni pubbliche) finisce paradossalmente col costituire buon viatico, da un lato, per l'introduzione o il rafforzamento di diseguaglianze e discriminazioni interne alla fenomenologia religiosa e, dall'altro, per il riproporsi di nuovi tentativi di frammentazione territoriale, a loro volta favoriti dalla perdurante inerzia del legislatore nazionale, ben poco propenso a considerare e soprattutto a fare valere lo stretto legame che intercorre tra tutela dei diritti

alle particolarità dell'esperienza di fede) a richiedere deroghe e adattamenti ragionevoli alla disciplina giuridica così detta di diritto comune. In questi casi, la cosiddetta specialità delle norme di diritto ecclesiastico non costituisce altro che concretizzazione dell'eguaglianza sostanziale. Rispetto a quest'ultima, è in effetti coerente ritenere che, di là dell'eventuale specializzazione in senso giuridico-formale (ovvero quanto alla fonte normativa utilizzata), la compresenza di un elemento religioso civilmente rilevante debba comportare un riadattamento, in senso conforme, della "regola generale di ordinaria irrilevanza civile delle qualificazioni religiose" (S. DOMIANELLO, L'utilità pratica del "Diritto ecclesiastico civile» come scienza, in Il nuovo volto del diritto ecclesiastico italiano, a cura di G. B. VARNIER, Rubbettino, Soveria Mannelli, 2004, p. 294).

${ }^{28}$ Cfr., per più profili, C. ELEFANTE, Fiscalità di vantaggio ed economia sociale religiosa nella dinamica dei rapporti tra diritto eurounitario e diritto interno. Principi consolidati e applicazioni controverse, in Quaderni di diritto e politica ecclesiastica, n. 3/2017, p. 665 ss.; EAD., Esenzioni di Stato e aiuti fiscali: il recupero dell'Ici sugli immobili degli enti ecclesiastici tra difficoltà e impossibilità, in Quaderni di diritto e politica ecclesiastica, n. 3/2018, p. 765 ss.; EAD., La "non commercialità" tributaria tra presente e futuro. Novità interpretative in materia di sgravi fiscali per attività socio-sanitarie degli enti religiosi in regime di convenzionamento con la pubblica amministrazione, in Quaderni di diritto e politica ecclesiastica, n. 3/2019, p. 717 ss.

${ }^{29}$ Cfr. i contributi presenti in Libertà di espressione e libertà religiosa in tempi di crisi economia e di rischi per la sicurezza, a cura di F. DAL CANTO, P. CONSORTI, S. PANIZZA, University Press, Pisa, 2016, e Le libertà spaventate. Contributo al dibattito sulle libertà in tempi di crisi, a cura di P. CONSORTI, F. DAl CANTO, S. PANIZZA, Pisa University Press, Pisa, 2016. 
fondamentali - ivi compreso il diritto di libertà religiosa - e principio della Repubblica una e indivisibile ${ }^{30}$.

E qui, possiamo aggiungere, l'attrazione verso il diritto comune, lungi dal determinare un avanzamento nell'eguale tutela della libertà religiosa, diviene sinonimo di conservazione dell'esistente. È ormai ben noto, infatti, come la condizione di confessione così detta intesizzata ovverosia firmataria di un'intesa ex art. 8, terzo comma, Cost. (o l'esistenza di un vincolo di appartenenza a essa, nel caso degli enti ecclesiasticireligiosi), costituisca l'elemento giuridico-formale che più di ogni altro consente di vedere soddisfatte le proprie legittime aspettative $\mathrm{e}$ in particolare di accedere alle prerogative previste dalla stessa legislazione di diritto comune (in particolare, quella che traduce operativamente l'indicazione di cui all'art. 118, quarto comma, Cost.). Quest'ultima quindi, a sua volta, finisce paradossalmente per rafforzare il diritto (speciale) bilateralmente convenuto ${ }^{31}$, fungendo da punto di riferimento per una sorta di effetto di trascinamento degli esiti di selezione e qualificazione connessi alla stessa bilateralità pattizia ${ }^{32}$.

Ne consegue in particolare che ad affiancare, a più livelli, le istituzioni pubbliche nel perseguimento degli interessi (non più pubblici ma) generali sono, fondamentalmente, i gruppi e le confessioni religiose ritenute più affidabili e accreditate, le quali si confermano interlocutrici privilegiate (se non uniche) delle prime ${ }^{33}$, in ciò determinando il rischio,

30 È esemplare al riguardo la legislazione regionale in tema di edilizia di culto, non a caso oggetto di significativi e ben noti interventi della Corte costituzionale, l'ultimo dei quali costituito dalla sentenza n. 54 del 2019 (per il quale si rimanda a N. MARCHEI, La Corte costituzionale chiude il cerchio e "smantella" la legge della regione Lombardia sugli edifici di culto, in Quaderni di diritto e politica ecclesiastica, n. 3/2019).

${ }^{31}$ M.C. FOLLIERO, Enti religiosi e non profit tra Welfare State $e$ Welfare Community. La transizione, Giappichelli, Torino, 2010.

${ }^{32}$ Che così vede rafforzarsi l'intervenuto sviamento concettuale e funzionale segnalato da S. DOMIANELLO, Libertà religiosa tra bilateralità necessaria, diffusa e impropria, in Le proiezioni civili delle religioni tra libertà e bilateralità, a cura di A. FUCCILLO, Editoriale Scientifica, Napoli, 2017, p. 35 ss. Più recente F. FRENI, I "nuovi accordi" Stato-confessioni in Italia tra bilateralità necessaria e diffusa, in Stato, Chiese e pluralismo confessionale, cit., n. 15 del 2020.

33 Sono quindi giustificati i dubbi circa il concetto stesso di minoranza religiosa avanzati da J. PASQUALI CERIOLI, (Non)conclusioni, cit., p. 182. Posto che «[c]on la nuova 'stagione', inaugurata nel decennio scorso, hanno avuto accesso agli strumenti di bilateralità pattizia, e sono stati dunque 'ammessi' a uno status giuridico di favore rispetto ai molti ancora esclusi dalle leggi "sulla base di intese", anche gruppi estranei al tessuto storico italiano", l'A. si chiede appunto "se per 'minoranze' dobbiamo intendere quelle realtà confessionali o "non confessionali" che, pur godendo di un seguito rilevante, siano 
da un lato, del riaffiorare di nuove prassi di ricorso strumentale da parte del potere politico al sostegno interessato delle religioni e, dall'altro, dell'emergere di ulteriori ostacoli per la tenuta delle libertà e dei diritti individuali. In questo contesto, appaiono tutt'altro che casuali, da un lato, il recupero della visione internazionalistica delle relazioni Stato-Chiesa e, in particolare, delle garanzie previste in sede concordatario-pattizia appannaggio della così detta libertà istituzionale della Chiesa (si allude in particolare, all'art. 2, n. 1 dell'Accordo di Villa Madama ${ }^{34}$ e, dall'altro, il suo (per la verità non così scontato) accostamento al principio della sussidiarietà orizzontale ${ }^{35}$.

Nel contempo, il rinnovato protagonismo pubblico delle religioni tende a massimizzare la tensione tra il momento collettivo-istituzionale e quello individuale dell'esperienza di fede, ampiamente intesa. Le nuove

percepite estranee a una tavola di valori 'rassicuranti' da parte di alcuni settori dei pubblici poteri, sensibili al presidio paternalistico di un asserito sentimento religioso diffuso. Solo in questo senso, forse, possiamo considerare mussulmani e atei 'minoranze'; si tratta, non a caso, di variegate comunità che hanno trovato, e continuano a trovare, $\mathrm{i}$ maggiori ostacoli al godimento effettivo di alcune libertà fondamentali che la Carta garantisce, invece, a tutti».

${ }^{34}$ Secondo il quale, com'è noto, "La Repubblica riconosce alla Chiesa cattolica la piena libertà di svolgere la sua missione pastorale, educativa e caritativa, di evangelizzazione e di santificazione. In particolare, è assicurata alla Chiesa la libertà di organizzazione, di pubblico esercizio del culto, di esercizio del magistero e del ministero spirituale nonché della giurisdizione in materia ecclesiastica".

${ }^{35} \mathrm{Si}$ vedano almeno, con varietà di accenti, G. DALLA TORRE, Enti ecclesiastici e Terzo settore. Annotazioni prospettiche, in Stato, Chiese e pluralismo confessionale, cit., n. 16 del 2018, p. 3 e A. BETTETINI, Tra autonomia e sussidiarietà: contenuti e precedenti delle convenzioni a carattere locale tra Chiesa e Istituzioni pubbliche, in Stato, Chiese e pluralismo confessionale, cit., maggio 2010, nonché, riguardo alla saldatura tra il succitato art. 2 dell'Accordo e la previsione del riformato art. 118, quarto comma, Cost., ID. Riflessi canonistici della riforma del Terzo settore, in Stato, Chiese e pluralismo confessionale, cit., n. 20 del 2018, pp. 6-7, e ID., Ente ecclesiastico, beni religiosi e attività di culto, Giuffrè-Francis Lefebvre, Milano, 2019, p. 29-20, laddove in particolare si afferma che l'eventuale mancata considerazione tra le "attività indubbiamente funzionali, in quanto rivolte a realizzare le finalità proprie della Chiesa" anche delle "attività previste dall'art. 2 n. 1 dell'Accordo di Villa Madama (libertà per la Chiesa di svolgere la propria missione pastorale, educativa, caritativa e santificatrice)" andrebbe riconosciuta come "viziata di incostituzionalità, per contrasto con $1^{\prime}$ art. $7,1^{\circ}$ comma, Cost. e anche con il riformato art. 118 Cost., che dà rilievo costituzionale al principio di sussidiarietà attribuendo alle persone e alle associazioni una specifica potestà di definire quali siano i fini di interesse generale da conseguire nell'ambito dell'ordinamento e di perseguirli in base alle loro peculiari autonomie e identità" (mio il carattere corsivo). 
forme di obiezione di coscienza, in cui a obiettare sono soggetti collettivi ${ }^{36}$, che in questo modo pretendono di azzerare il dissenso ideologico interno, costituiscono - in disparte ogni considerazione relativa alla reale portata del riferimento concettuale al fenomeno obiettorio - sintomo significativo di questo stato di fatto e quindi tema di studio e di analisi di estremo interesse.

\section{4 - Le conferme della pandemia. I limiti della libertà religiosa (e gli spunti per la valorizzazione del suo apporto costruttivo)}

A fronte di queste evidenze contraddittorie l'irrompere dell'emergenza pandemica ha il (paradossale) sapore della continuità.

Leggo in questo senso, in particolare, la sostanza del dibattito relativo alla compressione della libertà di culto (in forma pubblica e associata) determinata dai primi provvedimenti governativi di contenimento della pandemia (quelli, per intenderci, che hanno scandito l'imposizione del così detto lockdown ${ }^{37}$ ).

Al netto delle considerazioni relative alla "ragionevole incertezza interpretativa" che è derivata da un "pasticcio normativo" che ha travolto "insieme libertà e logica"38, al carattere (solo) indiretto della limitazione della libertà di culto determinata dai provvedimenti in questione ${ }^{39}$, alla necessità di contestualizzare l'impatto sulla libertà di culto "nell'ambito

${ }^{36}$ Utile al riguardo l'affaccio comparatistico: A. MADERA, Nuove forme di obiezione di coscienza fra oneri a carico della libertà religiosa e third-party burdens. Un'analisi comparativa della giurisprudenza della Corte Suprema U.S.A. e della Corte di Strasburgo, in Stato, Chiese e pluralismo confessionale, cit., n. 5 del 2017.

${ }^{37} \mathrm{~L}$ 'interesse manifestato al riguardo dagli ecclesiasticisti è stato in effetti immediato e significativo. In questa sede, ci si può limitare a richiamare, con salvezza dei più specifici riferimenti che seguiranno, i contributi confluiti nelle sezioni dedicate dei siti web, rispettivamente, del gruppo di ricerca DiReSom (Diritto e Religione nelle Società Multiculturali - Law and Religion in Multicultural Societies, www.diresom.com) e dell'Osservatorio delle libertà e delle istituzioni religiose (www.olir.it). Un'utile rappresentazione complessiva dei provvedimenti in questione e delle connesse criticità interpretative si trova in G. CASUSCELLI, Le fonti del diritto ecclesiastico italiano: intersezioni e interpretazioni in S. BERLINGÒ, G. CASUSCELLI, Diritto ecclesiastico, cit., p. $90 \mathrm{~s}$.

38 P. CONSORTI, La libertà religiosa travolta dall'emergenza, in Forum di Quaderni costituzionali, 2/2020 (www.forumcostituzionale.it), 25 maggio 2020, in particolare p. 379 s.

39 A. FERRARI, Covid-19 e libertà religiosa, in Settimana News (www.settimananews.it), 6 aprile 2020. 
del deficit di fondo, comune anche alle altre libertà"40 e al pesante condizionamento nella definizione della "scala delle priorità", determinato dalla situazione di necessità ${ }^{1}$, si mostra infatti tutt'altro che secondario il richiamo, da un lato, alle (peraltro risalenti) indicazioni della giurisprudenza costituzionale (sollecita nel sottolineare il carattere non assoluto dei singoli diritti e libertà previste in Costituzione) e, dall'altro, all'ampiezza del quadro dei principi e delle regole di natura costituzionale che afferiscono alla tutela del fenomeno religioso e che, in particolare, non possono che rimandare alle prescrizioni della Convenzione Europea dei Diritti dell'Uomo e del diritto dell'Unione Europea ${ }^{42}$.

E infatti, quanto alla CEDU, il suo art. 9, secondo comma, prevede com'è noto che la salute pubblica possa costituire limite opponibile alla "libertà di manifestare la propria religione o il proprio credo". Quanto poi al diritto dell'Unione Europea, a esso si è fatto puntuale e argomentato riferimento, più di recente, per ribadire il nesso stringente tra la doverosa tutela della salute e i principi europei di precazione e azione preventiva e, di qui, per sottolineare l'imprescindibilità dei criteri interpretativi attraverso i quali le istituzioni europee traducono l'esigenza di diffusa conformazione ai suddetti principi ${ }^{43}$. In questo modo - si può forse osservare ulteriormente - legittimità degli obiettivi perseguiti, necessità, adeguatezza e proporzionalità delle misure limitative idonee allo scopo, minore sacrificio, non costituiscono soltanto modalità tecnico-operative di traduzione dei limiti previsti dalle stesse disposizioni di garanzia ma assurgono più ampiamente a principi e criteri di riconoscimento e di concretizzazione del carattere costituzionalmente situato della libertà religiosa.

L'auspicato affermarsi di siffatti parametri interpretativi (attraverso un processo evolutivo che allo stato attuale non può che fare leva sull'apporto decisivo della giurisprudenza ma che necessiterebbe di

${ }^{40}$ N. COLAIANNI, La libertà di culto al tempo del coronavirus, in Stato, Chiese e pluralismo confessionale, cit., n. 7 del 2020, p. 28 s.

41 A. LICASTRO, Il Lockdown della libertà di culto pubblico al tempo della pandemia, in Consulta Online (www.giurcost.org), n. 1/2020.

42 Per entrambi i profili, G. CASUSCELLI, Gli "effetti secondari", cit., in particolare pp. 3-6, ivi puntuali riferimenti alle pronunce della Corte italiana e al diritto europeo.

43 In questo senso, G. CASUSCELLI, Gli "effetti secondari", cit., ove si ribadisce (p. 2-3) che "la preminente tutela della salute, diritto fondamentale degli individui e della collettività ai sensi del primo comma dell'art. 32 Cost., non può andare disgiunta da uno stretto coordinamento con i principi di precauzione e di azione preventiva, vincolanti nel diritto dell'Unione Europea, nel quadro della politica in materia ambientale". 
interventi dedicati del legislatore) trova ragioni di continuità evolutiva proprio in relazione all'estendersi quantitativo e qualitativo delle proiezioni civili della libertà religiosa ovvero della riconosciuta dimensione pubblica del fattore religioso e della conseguente necessità di ricondurne le concrete manifestazioni nell'alveo di una bilanciata valutazione dei diritti e degli interessi coinvolti, attenta alle peculiarità delle circostanze di fatto. Soprattutto esso sembra poter costituire risposta plausibile ed efficace al vuoto prodotto dalla sopravvenuta inadeguatezza - che proprio l'emergenza pandemica ci restituisce plasticamente ${ }^{44}$ - di un modo di procedere formalistico, per categorie astratte ma rigorosamente predefinite, allorquando si tratta di registrare e mettere in valore le scansioni operative dei diritti e delle libertà costituzionali ${ }^{45}$. Ciò vale a maggior ragione allorquando non si tratti più di discutere (in maniera che, per quanto appena esposto, può a questo punto risultare persino inappropriata) di limiti alla libertà religiosa ma si preferisca focalizzare l'attenzione sul contributo propositivo che ne può caratterizzare l'esercizio, rendendola idonea ad alimentare i processi di innovazione ordinamentale (nella continuità dei fini-valori).

E qui credo possa tornare utile estendere il campo materiale di queste riflessioni per soffermarsi brevemente sulla più recente versione di un tema classico del diritto ecclesiastico, che è tornato a far parlare di sé come a segnalare una sorta di beffardo ritorno alla normalità: quello dell'esposizione del crocifisso nelle aule scolastiche pubbliche. Mi riferisco, evidentemente, alla vicenda processuale sulla quale sono

44 Sembra in effetti difficile revocare in dubbio il fatto che il coronavirus abbia prodotto una alterazione del contesto sociale (e di conseguenza politico-istituzionale) tale per cui gesti normalmente considerati come manifestazioni di affetto e vicinanza umana hanno finito con l'assumere un significato ben diverso, talora persino opposto a quello che normalmente veniva loro assegnato, anche dall'ordinamento giuridico, sicché ciò che prima era consentito è poi stato vietato (o, all'opposto, è stato imposto ciò che prima era vietato: esemplare al riguardo il caso del velo islamico, sul quale M. RICCA, Don't Uncover that Face! Covid-19 Masks and the Niqab: Ironic Transfigurations of the ECtH's Intercultural Blindness, in Intercultural Journal for the Semiotics of Law, 30 April 2020, pp. 125). In questo senso, si può riconoscere che, in fondo, le difficoltà dell'emergenza pandemica sono anzitutto difficoltà di accedere a una lettura contestualizzata dell'effettivo significato degli atti e dei comportamenti da disciplinare.

45 Torna utile al riguardo l'osservazione per cui "[e]ssere e sentirsi liberi sono esperienze situate culturalmente perché sono relazioni [...] Quelle libertà sono valori appunto perché le attività e le corrispondenti esperienze psicologiche sono situate all'interno di un contesto di senso e di relazioni individuali, sociali [...] che potrebbero limitarne l'esercizio": M. RICCA, Oltre Babele, cit., p. 204 (corsivo non testuale). 
intervenute le Sezioni Unite della Cassazione con la recentissima sentenza n. 24414 dello scorso 9 settembre ${ }^{46}$.

Non è questa la sede per una puntuale valutazione della decisione della Corte, che in effetti appare densa di implicazioni, anche sistematiche, di rilievo e merita quindi di venire analizzata con molta attenzione e cautela. Per quanto ora interessa, mi sembra tuttavia di poter sostanzialmente riproporre le considerazioni che ero andato maturando, nell'imminenza di questo convegno, riflettendo sull'ordinanza di rimessione.

Ciò non prima di sottolineare, brevemente, come in realtà la fattispecie da cui origina la questione giunta all'esame delle Sezioni Unite presenti profili che possono dirsi almeno in parte inediti ${ }^{47}$.

Tra gli elementi più evidenti di novità, v'è senz'altro da annoverare il soggetto che lamenta l'illegittimità dell'esposizione del crocifisso nell'aula scolastica pubblica, dal momento che si tratta di un insegnante e, per di più, di un insegnante di una scuola secondaria superiore. A ciò si aggiunga che l'esposizione contestata è in questo caso sostanzialmente da ricondurre alla volontà espressa dalla maggioranza degli stessi studenti, che - con deliberato adottato in assemblea di classe - avevano richiesto di provvedere all'esposizione, durante l'orario delle lezioni. Tale volontà era stata recepita dal dirigente scolastico, che con apposito provvedimento, aveva disposto l'esposizione richiesta imponendo a tutto il corpo docente di attenersi alle nuove indicazioni ma in ciò incontrando il rifiuto del ricorrente, che a sua volta, invocando la propria libertà di coscienza e di insegnamento, aveva sistematicamente provveduto a rimuovere il crocifisso dall'aula prima di iniziare la propria lezione per poi, al termine della stessa, ricollocarlo al suo posto. Di qui, la sanzione disciplinare della

\footnotetext{
46 Sulla quale, tra i primi commenti, N. COLAIANNI, Dal "crocifisso di Stato" al "crocifisso di classe" (nota a margine di Cass., SS. UU., 9 settembre 2021, n. 24414), in Stato, Chiese e pluralismo confessionale, cit., n. 12 del 2021; M. TOSCANO, Il crocifisso 'accomodato'. Considerazioni a prima lettura di Corte cass., Sezioni Unite civili, n. 24414 del 2021, in Stato, Chiese e pluralismo confessionale, cit., n. 18 del 2021.

47 In questo senso, con varietà di accenti e in riferimento all'ordinanza interlocutoria della IV Sezione (Lavoro) che ha rimesso gli atti al Primo Presidente al fine di disporre l'intervento delle Sezioni Unite (la n. 19618 del 2020), A. LICASTRO, Il crocifisso e i diritti del lavoratore nell'ambiente scolastico (aspettando le Sezioni Unite della Cassazione), in Stato, Chiese e pluralismo confessionale, cit., $n .7$ del 2021; N. COLAIANNI, Il crocifisso di nuovo in Cassazione. Note da amicus curiae, in Stato, Chiese e pluralismo confessionale, cit., n. 12 del 2021; M. TOSCANO, Crocifisso nelle aule scolastiche: una fattispecie inedita al vaglio delle Sezioni Unite, in Quaderni di diritto e politica ecclesiastica, n. 3/2020, p. 887, nonché gli stessi giudici delle Sezioni Unite (Cass. SS.UU. n. 24414/2021, Svolgimento del processo, par. 5).
} 
sospensione dall'insegnamento per trenta giorni, inflitta al ricorrente dall'Ufficio Scolastico Provinciale, confermata nella sua legittimità dal Tribunale che, adito dal docente, aveva in particolare escluso il carattere discriminatorio della condotta tenuta dal dirigente scolastico.

Le Sezioni Unite sono quindi sostanzialmente chiamate a giudicare della compatibilità "con la libertà di insegnamento e di coscienza in materia religiosa, intesa quest'ultima anche come libertà negativa, da assicurare ad ogni docente" dell'ordine di esposizione del crocifisso impartito dal dirigente scolastico ${ }^{48}$ ma è inevitabile che esse finiscano, per quanto indirettamente, col coinvolgere significato e portata da ascrivere all'iniziativa degli studenti, da considerare a sua volta quale forma di manifestazione della propria libertà religiosa ${ }^{49}$.

Volendo sintetizzarne all'estremo le conclusioni, si può dire che la Suprema Corte, riconosciuta la formale vigenza dell'art. 118 del R.D. n. 965 del 1924, ha anzitutto rilevato l'illegittimità per incompatibilità con la laicità dello Stato (e quindi la disapplicazione al caso di specie ${ }^{50}$ ) dell'obbligatorietà dell'esposizione del crocifisso dalla stessa disposizione deducibile ${ }^{51}$ ma ha nel contempo ritenuto che quest'ultima sia suscettibile di interpretazione "in senso conforme alla Costituzione e alla legislazione che dei principi costituzionali costituisce svolgimento e attuazione" 52 . Con

48 "Si tratta di stabilire se la determinazione del dirigente scolastico, rivolta a tutti gli insegnanti della classe, si ponga in contrasto con il principio della libertà di insegnamento del docente dissenziente che desideri fare lezione senza essere costretto nella matrice religiosa impressa dal simbolo affisso alla parete, e collida con il divieto di discriminazione su base religiosa" (Cass. SS.UU. n. 24414/2021, Svolgimento del processo, par. 1).

49 Sottolinea che tale individuazione del thema decidendum è "più precisa e puntuale" di quella prospettata, nel bilanciamento tra "la libertà di insegnamento" e il "rispetto della coscienza civile e morale degli alunni", dalla già citata ordinanza interlocutoria n. 19618 del 2020, M. TOSCANO, Il crocifisso 'accomodato', cit., p. 49 (che richiama le considerazioni critiche formulate in M. TOSCANO, Crocifisso nelle aule scolastiche, cit., $\mathrm{p}$. 889-890).

50 N. COLAIANNI, Dal "crocifisso di Stato", cit., p. 18-19.

51 In buona sostanza, "[l']esposizione autoritativa del crocifisso nelle aule scolastiche non è compatibile con il principio supremo di laicità dello Stato. L'obbligo di esporre il crocifisso è espressione di una scelta confessionale. La religione cattolica costituiva un fattore di unità della nazione per il fascismo; ma nella democrazia costituzionale l'identificazione dello Stato con una religione non è più consentita".

52 Cass. SS.UU. n. 24414/2021, Motivazioni della decisione, par. 11.4. E quindi (par. 12.1): "[1]a disposizione regolamentare non può più essere letta come implicante l'obbligo di esporre il crocifisso nelle scuole, ma va interpretata nel senso che l'aula può accoglierne la presenza allorquando la comunità scolastica interessata valuti e decida in autonomia di 
la conseguenza per cui l'esposizione del crocifisso nell'aula scolastica pubblica è invece ritenuta possibile laddove sia da ricondurre a una autonoma decisione della comunità scolastica interessata, "con valutazione che sia frutto del rispetto delle convinzioni di tutti i componenti della medesima comunità, ricercando un "ragionevole accomodamento" tra eventuali posizioni difformi» ${ }^{53}$.

Correlativamente, ad avviso dei Supremi giudici, al singolo dissenziente non compete "un potere di veto assoluto", dal momento che

"[1]a libertà di manifestazione della propria convinzione non religiosa non richiede e non si realizza attraverso il divieto assoluto di affissione o l'obbligo di rimozione del simbolo religioso esposto in uno spazio pubblico condiviso a soddisfazione di un interesse di altri soggetti"54.

Ciò significa, in buona sostanza, che la decisione della maggioranza degli studenti non può essere ritenuta di per sé sola idonea a legittimare la presenza del crocifisso sui muri della scuola (né tantomeno a imporre il provvedimento del dirigente scolastico alla coscienza dell'insegnante, legittimando la sanzione inflitta) ${ }^{55}$, richiedendosi diversamente che essa risulti concretamente in grado di garantire, sia sotto il profilo procedurale che dal punto di vista sostanziale, il rispetto della coscienza e dei

esporlo, nel rispetto e nella salvaguardia delle convinzioni di tutti, affiancando al crocifisso, in caso di richiesta, gli altri simboli delle fedi religiose presenti all'interno della stessa comunità scolastica e ricercando un ragionevole accomodamento che consenta di favorire la convivenza delle pluralità. La disposizione regolamentare sugli arredi scolastici è suscettibile di esprimere un significato conforme al nuovo contesto costituzionale e alla legislazione che dei principi costituzionali costituisce svolgimento e attuazione, in base a una interpretazione evolutiva che tramuta l'obbligo di esposizione del crocifisso in una facoltà, affidando alle singole comunità scolastiche la decisione circa la presenza dei simboli religiosi nelle proprie aule". Si tratta di un elemento centrale nell'iter argomentativo della Corte, destinato a far discutere. Secondo M. TOSCANO, Il crocifisso 'accomodato', cit., p. 52-53 si tratta di un "vizio di partenza (che) produce ricadute su tutta la logica argomentativa della pronuncia e in qualche misura ne intacca la tenuta generale, nonostante nel complesso le Sezioni Unite si siano mosse in direzione condivisibile".

53 Così il principio di diritto espresso dalla Corte (Cass. SS.UU. n. 24414/2021, Motivazioni della decisione, par. 30).

${ }^{54}$ Cass. SS.UU. n. 24414/2021, Motivazioni della decisione, par. 21.

55 Atteso che, come si è persuasivamente osservato, ad argomentare diversamente «[s]i darebbe spazio [...] al dominio della maggioranza anche in questioni di coscienza, laddove, "non valendo il numero, s'impone ormai la pari protezione della coscienza di ciascuna persona"» N. COLAIANNI, Il crocifisso di nuovo, cit., p. 17. 
convincimenti altrui. Neppure però può dirsi consentito al docente dissenziente di opporsi legittimamente a una decisione (della maggioranza) degli studenti che soddisfi tali condizioni e si appalesi pertanto quale frutto di un adeguato e convincente bilanciamento dei diritti e degli interessi in gioco, perseguito anche attraverso l'effettivo coinvolgimento del dissenziente stesso nella decisione finale adottata ${ }^{56}$.

Questa duplice sottolineatura torna utile nel contesto argomentativo che stiamo sviluppando, dal momento che consente di sottolineare e assumere a un più ampio orizzonte sistematico l'importanza prospettica dell'interazione possibile tra compagine studentesca, corpo docente e autorità scolastica posta al vaglio della Corte, aggiungendo significativi (per quanto problematici) elementi di riscontro a quanto segnalato sinora a proposito della portata innovativa, nella continuità dei fini-valori ordinamentali, ascrivibile alla libertà (di coscienza e) di religione.

Vale a questo proposito considerare che la posizione assunta dalle Sezioni Unite aiuta a comprendere come l'iniziativa degli studenti non debba essere di necessità deprivata di qualsiasi possibile significato costruttivo e ciò anche in considerazione del fatto che la scuola è deputata alla formazione della personalità degli alunni e alla promozione dello spirito democratico, fatto anche di tolleranza reciproca e di confronto/scontro aperto e leale tra opinioni differenti.

Con questi presupposti, sembrerebbe in effetti eccessivo derubricare aprioristicamente il deliberato dell'assemblea studentesca a mero atto di sopraffazione nei confronti dei credenti non cattolici, dei non credenti e agnostici nonché degli stessi credenti cattolici che, per avventura, ritengano che non sia il caso di esporre il crocifisso nell'aula scolastica pubblica quando invece proprio l'iniziativa degli studenti può rappresentare un primo passo per una discussione che può anche condurre a soluzioni - innovative in quanto non predeterminate - che abbiano l'effetto di salvaguardare la libera espressione del pensiero e la libertà di coscienza di tutti e di ciascuno. Allo stesso modo, il contegno

\footnotetext{
56 "Affidare la soluzione del conflitto tra i diritti ora alla semplice prevalenza del gruppo più numeroso ora al potere di veto assoluto e paralizzante del singolo va incontro allo stesso limite. L'una e l'altro non raccolgono la sfida e l'opportunità della convivenza in un contesto caratterizzato da una pluralità di fedi e di convinzioni esplicitamente areligiose; e non rispondono all'idea della tolleranza verso l'altro orientata dalla capacità di ascolto e dalla disponibilità di ciascuno di rendersi punto mediano e di mediazione tra due opposti apparentemente inconciliabili": Cass. SS.UU. n. 24414/2021, Motivazioni della decisione, par. 21.1.
} 
assunto dall'insegnante, laddove egli si è limitato a rimuovere il crocifisso per il tempo della sua lezione salvo riporlo al proprio posto immediatamente dopo la fine della lezione stessa, può essere valutato quale proposta costruttiva nella direzione dell'adozione di soluzioni equilibrate e convincenti ${ }^{57}$.

In effetti, quale correttivo all'operare della regola di maggioranza nel campo dei diritti fondamentali58, la strada del bilanciamento improntato (anche qui) a proporzionalità e ragionevolezza (ovvero il criterio e il metodo dell'accomodamento ragionevole ${ }^{59}$ ), suggerita dalla Corte, si propone quale strumento utile alla valorizzazione non egemonica degli interessi in gioco ${ }^{60}$.

57 Peraltro, la stessa Corte (par. 22 delle motivazioni) sottolinea la molteplicità delle modalità di affissione del crocifisso, menzionando in particolare: "(a) l'affissione sulla parete della stessa aula, accanto al crocifisso, di un simbolo o di una frase capace di testimoniare l'appartenenza al patrimonio della nostra società anche della cultura laica; (b) la diversa collocazione spaziale del crocifisso, non alle spalle del docente; (c) l'uso non permanente della parete, con il momentaneo spostamento del crocifisso, in modi formalmente e sostanzialmente rispettosi del significato del simbolo per la coscienza morale degli studenti, durante l'orario di lezione dell'insegnante dissenziente".

58 «La regola di maggioranza senza correttivi non può utilizzarsi nel campo dei diritti fondamentali, che è dominio delle garanzie per le minoranze e per i singoli. I diritti fondamentali svolgono un ruolo contro-maggioritario, sicché, abbandonato il criterio quantitativo, il "peso" assunto dai soggetti coinvolti non può fare ingresso quale decisivo criterio di bilanciamento delle libertà. Anche nelle formazioni sociali ove si svolge la personalità del singolo, la libertà religiosa che accompagna questo sviluppo della persona umana non può essere governata dal criterio della maggioranza che prevale e della minoranza che capitola» (par. 20 delle motivazioni della decisione).

59 Sulla categoria della reasonable accomodation N. COLAIANNI, Dal "crocifisso di Stato", cit., p. 20, ove peraltro sottolinea che, in realtà, "l'accomodamento ragionevole prescritto dalla Corte non può intendersi in senso tecnico", atteso che nell'ottica della Corte il punto di partenza è costituito dalla parete bianca (e non già dall'esposizione obbligatoria, nel qual caso ci troveremmo appunto dinanzi a una ipotesi di prescrizione normativa da adattare al fine di preservare la libertà del dissenziente e quindi di accomodamento strettamente inteso). "In sostanza" - l'A. precisa ulteriormente «l'espressione utilizzata, e introdotta direttamente nella massima di diritto, dalle Sezioni unite, rimanda alla transazione privatistica delle opposte pretese (aliquid datum aliquid retentum) o, in generale, al classico "equo contemperamento" (n. 23.1) degli opposti interessi o bilanciamento dei diritti fondamentali di ciascuno eventualmente confliggenti».

${ }^{60}$ Sotto questo profilo, vale ribadire che il punctum dolens della particolare vicenda che ha richiesto l'intervento delle Sezioni Unite consiste in larga parte - come in effetti la stessa Corte evidenzia con chiarezza - nell'atteggiamento acriticamente adesivo del dirigente scolastico, che si è limitato a recepire il deliberato dell'assemblea studentesca, conferendo a essa la forma e il valore del provvedimento amministrativo e imponendone 
L'attenzione si sposta quindi sulle condizioni, di fatto ma soprattutto giuridiche, che consentono all'interazione tra le diverse manifestazioni di libertà implicate nel caso concreto di risultare fruttuosa in quanto effettivamente rispettosa della caratterizzazione democraticopluralista dell'ordinamento e della portata inclusiva e dialogante della sua laicità. E qui ci si può fondatamente interrogare sull'opportunità (e finanche sulla legittimità della eventuale scelta) di affidarsi in tutto e per tutto alle autonome determinazioni (e alle capacità di mediazione) dell'istituzione scolastica ${ }^{61}$, per quanto alimentate dalla partecipazione democratica del corpo docente e della compagine studentesca, senza preoccuparsi di ancorare gli esiti per tale via raggiunti a più esplicite coordinate normative che garantiscano non già l'omologazione ${ }^{62}$ delle soluzioni adottate ma la loro comune rispondenza sostanziale ai principi (unitari) di eguaglianza e non discriminazione nonché, nello specifico, al doveroso rispetto della legalità nell'esercizio delle funzioni pubbliche ${ }^{63}$. L'esplicito richiamo della Corte stessa al principio della sussidiarietà orizzontale $^{64}$ - che in effetti colpisce e avrebbe forse meritato qualche precisazione ulteriore - va probabilmente letto in questa dimensione prospettica e comunque tenendo conto di queste cautele ${ }^{65}$.

l'indiscriminato rispetto, tal quale, a tutti, docenti e studenti che fossero. Ovvero, se si preferisce, nella testimoniata difficoltà del sistema scolastico attuale ad assecondare il libero confronto delle idee e delle opinioni e ad alimentare una sintesi (pubblica) adattiva e concretamente inclusiva delle libertà, dei diritti e degli interessi in gioco.

${ }^{61} \mathrm{E}$ ciò a prescindere dalla così detta "procedimentalizzazione della scelta".

62 La circostanza è sottolineata esplicitamente dalla Corte, a corroborare il riferimento all'autonomia dell'istituzione scolastica (si veda in particolare il paragrafo 14 delle motivazioni).

63 È cioè auspicabile che le coordinate essenziali di riferimento entro cui la composizione adattiva degli interessi implicati va a essere collocata così come le procedure da seguire a tal fine non vengano lasciate nella totale disponibilità dell'istituzione scolastica ma restino di competenza del legislatore.

64 "L'originario carattere assoluto e incondizionato della esposizione del simbolo cristiano cede il posto alla possibilità di risposte articolate e non uniformanti, in base a una linea di composizione dei possibili conflitti all'interno della istituzione scolastica, secondo il principio base della sussidiarietà orizzontale che trova spazio e riconoscimento nell'art. 118 Cost." (Cass. SS.UU. n. 24414/2021, par. 12.1 dei motivi della decisione).

${ }^{65}$ Non sembra, in particolare, che la connotazione pubblica della funzione docente ovverosia la sua portata, per così dire, esterna in quanto potenzialmente coinvolgente anche soggetti che non fanno parte della compagine studentesca, del corpo docente e del personale amministrativo (cui si aggiunge il carattere istituzionale dell'edificio scolastico) costituisca elemento del tutto irrilevante nell'orientare la scelta tra le opzioni di esposizione astrattamente prospettabili, che quindi non può essere tarata unicamente 
Si tratta, in tutta evidenza, di questioni di particolare delicatezza, che peraltro vanno poste in relazione alle radicali trasformazioni del contesto di riferimento, a cominciare da quelle che convergono nell'ormai consumata crisi della tradizionale rappresentanza politica e delle relative istituzioni ${ }^{66}$. Di là di ciò (e preso atto altresì che, allo stato, è ancora una volta al giudice che tocca colmare i vuoti lasciati aperti dall'inerzia del legislatore), resta il fatto che il più recente capitolo della vicenda del crocifisso restituisce significative indicazioni prospettiche circa le virtù costruttive delle proiezioni esterne della coscienza (anche) religiosa e il suo potenziale porsi quale viatico per un innalzamento qualitativo nella salvaguardia promozionale del pluralismo e del fine-valore della persona umana.

Ciò nel momento in cui proprio grazie all'emergenza pandemica il perimetro, per così dire, ambientale del confronto si mostra in tutta la sua fluidità: la rimozione del crocifisso dall'aula scolastica per il solo tempo di svolgimento della lezione del docente obiettore (o, se si preferisce, la sua esposizione durante il tempo di svolgimento delle lezioni rimanenti) anticipa ciò che è poi accaduto (e accade) nel tempo dell'emergenza e, specificamente, della didattica a distanza (ovvero del così detto smart working) laddove spazio privato e funzione pubblica si intersecano e sovrappongono in maniera tale da costituire un tutt'uno e da rendere ancora più complessa e ardua la soluzione di eventuali conflitti di coscienza studenti-docenti ovvero fruitori-fornitori del servizio pubblico. Ripropone e rafforza, cioè, l'idea di una continua ridefinizione della dicotomia pubblico-privato (in senso sia spaziale che funzionale) e delle esigenze di regolamentazione che assumano tale dicotomia a principale criterio di riferimento.

Peraltro, anche per tali ipotesi, la necessità di tenere conto, in maniera elastica e flessibile, della labilità e della continua mutevolezza dei contesti e delle situazioni di fatto da disciplinare, accedendo a una valutazione realistica e sostanziale dei diritti e degli interessi coinvolti, rende auspicabile il ricorso a principi e criteri operativi (normativamente delineati) in grado di registrare e tenere in debito conto le particolarità

sulle esigenze emerse all'interno di una specifica comunità scolastica.

$66 \mathrm{Si}$ veda, per una significativa esemplificazione delle ricadute ecclesiasticistiche di una trasformazione che vede il "sistema politico basato non più sulla sovranità popolare bensì sul sostegno e il controllo di forti gruppi di interessi economici, sociali, religiosi", A. VITALE, Costituzione e ordinamenti confessionali. La relazione verticale, in M.C. FOLLIERO, A. VITALE, Diritto ecclesiastico. Elementi. Principi non scritti. Principi scritti. Regole. Quaderno 2 I principi scritti, Giappichelli, Torino, 2013, p. 108-109. 
delle singole fattispecie (interessante al riguardo, pur nella differenza del contesto giuridico-istituzionale, le indicazioni provenienti dall'esperienza statunitense $\left.{ }^{67}\right)$.

\section{5 - Il rafforzamento e l'estensione del paradigma collaborativo}

La risposta ordinamentale alle esigenze emergenziali di contenimento della pandemia ha dato vita a un dibattito che non ha riguardato unicamente la questione dei limiti alla libertà di esercizio in forma pubblica e associata del culto ma ha coinvolto i temi dell'autonomia confessionale e delle relazioni istituzionali Stato-Chiesa-confessioni religiose.

Con varietà di accenti e precisazioni, l'attenzione è andata così focalizzandosi, di volta in volta, sulle prerogative di natura internazionale poste a presidio della sovranità della Santa Sede e a garanzia della libertas Ecclesiae68, sul generale principio di autonomia confessionale e sulla doverosità costituzionale della regolamentazione pattizia dei rapporti tra lo Stato e le confessioni religiose (il principio così detto di bilateralità necessaria o pattizia) o ancora sul principio di collaborazione di cui all'art. 1 dell'Accordo di Villa Madama per evidenziare (in taluni casi, lamentare) il fatto che i provvedimenti di gestione dell'emergenza pandemica siano stati adottati unilateralmente dallo Stato e quindi senza alcun coinvolgimento delle autorità confessionali, come invece avrebbe dovuto essere in considerazione dei suddetti principi ${ }^{69}$.

Peraltro, a stemperare almeno per taluni aspetti i toni più aspri del dibattito sull'argomento sono intervenuti, favoriti dal subentrare di una

${ }^{67}$ Ovvero, in particolare, il ricorso, ivi, al così detto endorsement test.

${ }^{68}$ V. PACILLO, La sospensione del diritto di libertà religiosa nel tempo della pandemia, in Osservatorio delle libertà e delle istituzioni religiose (wwww.olir.it), 16 marzo 2020; ID., La libertà di culto al tempo del coronavirus: una risposta alle critiche, in Stato, Chiese e pluralismo confessionale, cit., n. 12 del 2021. Approfondimenti, non privi di note critiche, al riguardo in F. BOTTI, Bagattelle per una pandemia, in Stato, Chiese e pluralismo confessionale, cit., $\mathrm{n}$. 10 del 2021.

69 Cfr. M. d'ARIENZO, Intervista in Korazym.org, 15 maggio 2020, laddove, con riferimento ai protocolli di cui immediatamente nel testo, si evidenzia che "[l]a sospensione delle cerimonie religiose, se disposta in mancanza di preventive consultazioni con le Autorità confessionali, costituisce senz'altro una lesione della loro autonomia e del principio di necessaria bilateralità, come garantiti dalla Costituzione Italiana e dalle normative pattizie. Tale possibile violazione è stata tuttavia superata dal principio di leale e reciproca collaborazione delle Confessioni con lo Stato". 
nuova fase di contenimento della pandemia, i protocolli firmati dal Ministero dell'Interno con la Chiesa cattolica e con i rappresentanti delle confessioni religiose diverse dalla cattolica per la ripresa delle celebrazioni ${ }^{70}$. In realtà, anche questi protocolli - con cui, in buona sostanza, si è provveduto a tradurre operativamente le indicazioni normative di ordine generale, rapportandole alle specifiche esigenze rituali delle comunità di fede sottoscrittrici - hanno dato luogo a qualche discussione $^{71}$ ma sono stati prontamente inquadrati nell'alveo della partecipazione amministrativa, a volerne con ciò segnalare la sostanziale estraneità alla logica della bilateralità strettamente intesa e, per tale via, la loro piena riconducibilità nell'ordine proprio dello Stato e quindi la piena discrezionalità di quest'ultimo nell'accedervi ${ }^{72}$.

Ciò peraltro, a mio modo di vedere, non esclude che tali protocolli possano comunque essere considerati quale espressione di un più generale principio di collaborazione, in parte sganciato dalla pur fondamentale indicazione dell'art. 1 dell'Accordo di Villa Madama. In questo senso, essi indicano la tendenza alla progressiva inclusione dello stesso paradigma collaborativo nel contesto dei generali processi di democratizzazione del pubblico potere amministrativo e, più ampiamente, nelle dinamiche di trasformazione della sovranità statuale (interna ma anche esterna ${ }^{73}$ ).

70 Per una panoramica sui contenuti dei protocolli in questione, L. DECIMO, La "stagione" dei protocolli sanitari tra Stato e confessioni religiose, in www.olir.it, 14 maggio 2020; A. TIRA, Normativa emergenziale ed esercizio pubblico del culto. Dai protocolli con le confessioni diversi dalla cattolica alla legge 22 maggio 2020, n. 35, in Giustizia insieme, 8 giugno 2020 (www.giustiziainsieme.it).

${ }^{71}$ Cfr. G. MACRÌ, Brevi considerazioni in materia di governance delle pratiche di culto tra istanze egualitarie, soluzioni compiacenti e protocolli (quasi) "fotocopia", in Stato, Chiese e pluralismo confessionale, cit., n. 11 del 2021; M.L. LO GIACCO, I "Protocolli per la ripresa delle celebrazioni delle confessioni religiose diverse dalla cattolica": una nuova stagione nella politica ecclesiastica italiana, in Stato, Chiese e pluralismo confessionale, cit., n. 11 del 2021.

72 Cfr. N. COLAIANNI, Il sistema delle fonti costituzionali del diritto ecclesiastico al tempo dell'emergenza (e oltre?), in Rivista AIC (www.aic.it), n. 4/2020; F. ALICINO, Costituzione e religione in Italia al tempo della pandemia, in Stato, Chiese e pluralismo confessionale, cit., n. 19 del 2020; ID., La disciplina giuridica delle minoranze religiose (escluse). Le diseconomie esterne del favor religionis, in Stato, Chiese e pluralismo confessionale, cit., n. 13 del 2021; G. CIMBALO "A chiare lettere - Confronti" - Il papa e la sfida della pandemia, in Stato, Chiese e pluralismo confessionale, cit., n. 9 del 2020, p. 15 nonché, con utili approfondimenti tecnicoprocedurali, ID., Ortodossia, pandemia e legislazione degli Stati dell'Est Europa a tutela della salute, in Stato, Chiese e pluralismo confessionale, cit., n. 15 del 2021, p. 20 sub nota 2.

73 A tale ultimo proposito, con specifico riguardo a profili ecclesiasticistici, P. CAVANA, Le Sezioni Unite della Cassazione e l'art. 11 del Trattato lateranense, in Stato, Chiese e pluralismo confessionale, cit., 7 maggio 2012, in particolare 18 ss.; J. PASQUALI CERIOLI, 
Si può cioè dire che il principio di collaborazione rappresenti ormai un vero e proprio principio di sistema e in quanto tale regoli (non solo le relazioni tra ordinamenti ovvero tra Stato e gruppi religiosi ma) in senso ampio l'interazione tra gli ordini del sacro e del secolare, pur mantenendone ferma la distinzione costituzionalmente doverosa ${ }^{74}$. In ciò la vicenda della collaborazione ecclesiasticistica viene a collocarsi nel contesto di un più ampio percorso evolutivo che ha portato al riconoscimento e all'affermazione di un generale principio di collaborazione ordinamentale o sistemica.

Poco sposta, a tale ultimo riguardo, il fatto che nel caso dei soggetti religiosi non ci si trovi certo di fronte a enti costitutivi della Repubblica nel senso di cui all'art. 114 Cost. e neppure, a maggior ragione, nell'ambito di relazioni tra amministrazioni pubbliche. Tanto perché, in buona sostanza, nel caso delle relazioni ecclesiasticistiche l'istanza collaborativa assolve a una funzione non lontana da quella prevista nel contesto delle relazioni autonomistiche (ovvero, tipicamente, dall'art. 120 Cost.) e, più in generale dalla collaborazione infraistituzionale, dal momento che essa è pur sempre intesa garantire la salvaguardia di una fondamentale esigenza di unità ordinamentale a fronte della possibile frammentazione derivante dal riconoscimento di prerogative costituzionalmente garantite (nel nostro caso, di sovranità/indipendenza ovvero di autonomia confessionale). Sotto tale profilo, non è certo casuale la decisa sottolineatura del nesso che

Giurisdizione italiana ed "enti centrali della Chiesa Cattolica": tra immunità della Santa Sede e (intatta) sovranità dello Stato in re temporali in Stato, Chiese e pluralismo confessionale, cit., $\mathrm{n}$. 34 del 2017. Un interessante banco di prova delle ricadute ecclesiasticistiche delle trasformazioni del paradigma della sovranità è costituito dai processi di riforma che investono, ad esempio, i rapporti tra diritto canonico e diritto vaticano (illuminanti al riguardo le considerazioni iniziali di G. DALLA TORRE, Aspetti della giustizia vaticana, in Stato, Chiese e pluralismo confessionale, cit., maggio 2013) alimentando non poche incertezze interpretative e di ricostruzione sistematica (cfr. G. BONI, Il Diritto penale della Città del Vaticano. Evoluzioni giurisprudenziali, nel volume dal medesimo titolo a cura di G. DALLA TORRE, G. BONI, Giappichelli, Torino, 2014, in particolare p. 136 s.).

74 È appena il caso di avvertire - a evitare fraintendimenti non voluti - che l'ampiezza del riferimento collaborativo nulla toglie alla specificità del principio della bilateralità così detta necessaria o pattizia, al quale si è già fatto cenno in precedenza nel testo e per la quale si rimanda nuovamente ai riferimenti dettagliati retro sub nota 31, né alla connotazione comune della disciplina che governa i comuni strumenti della bilateralità così detta amministrativa. Si vuole invece attirare l'attenzione sul fatto che l'ancoraggio delle relazioni amministrative che possono instaurarsi tra le istituzioni pubbliche e i soggetti religiosi al principio ecclesiasticistico di collaborazione non sia da considerare del tutto privo di significato, quantomeno sul piano ricostruttivo generale. 
lega doverosamente il principio della sana e leale collaborazione al principio costituzionale di solidarietà 75 .

Anche in questo caso, quindi, si assiste al progressivo consolidamento di un fenomeno di attrazione dei principi specificamente destinati a governare le relazioni tra ordinamento giuridico e interessi religiosi verso più ampi principi di sistema e moduli operativi di diritto comune. E anche in questo caso, si tratta di tendenza che vale come riconoscimento di una più ampia rilevanza del fattore religioso ma che, allo stesso tempo, opera anche come una sorta di contrappeso nei suoi confronti.

In questo senso, il principio ecclesiasticistico di collaborazione risponde a due finalità concorrenti e solo apparentemente contraddittorie. Esso cioè costituisce buon tramite per assecondare il protagonismo delle religioni ma può rappresentare anche un efficace strumento di affermazione delle ragioni della sintesi pubblica (se si preferisce, della sovranità dello Stato), fungendo da argine nei confronti del rischio di indebite invasioni di campo.

Naturalmente, molto dipende da una serie di fattori quali, di volta in volta, il particolare titolo di attivazione dell'istanza collaborativa, il grado di trasversalità dell'interesse religioso da salvaguardare e la veste giuridica attraverso cui la collaborazione stessa si manifesta ${ }^{76}$. Ad esempio, non è indifferente che il rapporto collaborativo si collochi formalmente sul piano internazionalistico o su quello interno, né che sia inteso a soddisfare esigenze di tutela riferibili, in maniera prevalente, ai cittadini-fedeli o all'istituzione religiosa.

A risultare decisiva è però in ogni caso l'effettiva disponibilità dell'ordinamento giuridico (ovvero delle istituzioni pubbliche) ad assumere la pratica della collaborazione a una visione più ampia, tale da consentire a soggetti e fini religiosi di contribuire lealmente alla concretizzazione dei valori-fini costituzionali ma allo stesso tempo di impedire che per tale via vengano a determinarsi esiti irrispettosi dei principi di eguale libertà e di pluralismo democratico.

Presenta non pochi spunti di interesse al riguardo la nota verbale con la quale la Santa Sede - attraverso la Segreteria di Stato, sezione

75 G. CASUSCELLI, La crisi economica e la reciproca collaborazione tra le Chiese e lo Stato per "il bene del Paese", in Stato, Chiese e pluralismo confessionale, cit., ottobre 2011.

76 Cfr. G. CASUSCELLI, Il diritto ecclesiastico italiano "per principi": profili teorici e processi autoritativi di attuazione, in S. BERLINGÒ, G. CASUSCELLI, Diritto ecclesiastico, cit., p. 149 s. 
rapporti con gli Stati - ha inteso rappresentare al Governo italiano la propria posizione ufficiale nei confronti del disegno di legge n. 2005 (così detto Zan), recante "misure di prevenzione e contrasto della discriminazione e della violenza per motivi fondati sul sesso, sul genere, sull'orientamento sessuale, sull'identità di genere e sulla disabilità"77.

Anche in questo caso, mi limito a osservazioni di più immediata utilità per il tema che ci occupa. Esse lasciano impregiudicata ogni riflessione sui contenuti del ddl Zan, che, naturalmente, in questa sede non verranno presi in considerazione.

Considero quindi che, di primo acchito, l'iniziativa della Santa Sede sembra chiamare in causa il tema di fondo del rispetto delle prerogative sovrane dello Stato italiano. Più concretamente, si è da subito dubitato della pertinenza della via diplomatica percorsa per rappresentare allo Stato italiano l'avvertita esigenza di un ripensamento di alcuni contenuti del ddl e, di qui, della stessa legittimità di un intervento che, nella sostanza, sembra destinato a interferire con l'esercizio dei sovrani poteri del Parlamento e in questo senso potrebbe integrare un'ingerenza (e quindi una violazione degli obblighi internazionali) ${ }^{78}$.

77 I termini essenziali della questione sono ampiamente noti. In buona sostanza, atteso che, ad avviso della Santa Sede, il provvedimento in approvazione avrebbe "1'effetto di incidere negativamente sulle libertà assicurate alla Chiesa cattolica e ai suoi fedeli dal vigente regime concordatario", la nota auspica "che la Parte italiana possa [...] trovare una diversa modulazione del testo normativo continuando a garantire il rispetto dei Patti Lateranensi, che da quasi un secolo regolano i rapporti tra Stato e Chiesa e ai quali la stessa Costituzione repubblicana riserva una speciale menzione". Tanto perché, nella prospettazione della Santa Sede, «la criminalizzazione delle condotte discriminatorie per motivi "fondati sul sesso, sul genere, sull'orientamento sessuale, sull'identità di genere"», si porrebbe in potenziale contrasto con la garanzia assicurata dall'art. 2, primo e secondo comma, dell'Accordo del 1984 a presidio, rispettivamente, della piena libertà della Chiesa cattolica "di svolgere la sua missione pastorale, educativa e caritativa, di evangelizzazione e di santificazione" ovvero, in particolare, "di organizzazione, di pubblico esercizio del culto, di esercizio del magistero e del ministero spirituale, nonché della giurisdizione in materia ecclesiastica" e della "piena libertà di riunione e di manifestazione del pensiero, con la parola, lo scritto e ogni altro mezzo di diffusione", garantita "ai cattolici e alle loro organizzazioni e associazioni". La nuova tipizzazione normativa contrasterebbe infatti, con le "espressioni della Sacra Scrittura e delle tradizioni ecclesiastiche del magistero autentico del Papa e dei vescovi, che considerano la differenza sessuale, secondo una prospettiva antropologica che la Chiesa cattolica non ritiene disponibile perché derivata dalla stessa Rivelazione divina".

78 È in effetti difficile sfuggire alla sensazione per cui, in buona sostanza, la Santa Sede abbia sbagliato destinatario, atteso che è al Parlamento e non al Governo che compete l'esercizio del potere legislativo: N. COLAIANNI, "A chiare lettere - Editoriali". La Santa Sede e il d.d.l. Zan sulla tutela di LGBTQ, in Stato, Chiese e pluralismo confessionale, cit., n. 13 
Mi chiedo tuttavia se, al netto delle perplessità e dei rilievi critici che pur possono essere mossi nei confronti dell'iniziativa della Santa Sede $^{79}$, non si possa pensare ${ }^{80}$ che attraverso di essa si sia inteso dare formale avvio a un rapporto collaborativo e, soprattutto, che la circostanza lasci comunque impregiudicata la piena sovranità decisionale in capo allo Stato (ovverosia la potestà legislativa del Parlamento) ${ }^{81}$. Mi chiedo cioè, in buona sostanza, se non sia il caso di limitarsi a registrare l'effettività di apporto che la nota stessa può offrire in termini di arricchimento del dibattito pubblico, che in tal modo risulta, nei fatti, maggiormente plurale 82 .

Dico questo perché mi interessa soffermare l'attenzione sul fatto che, per quanto possa sembrare eccessiva, la tendenza espansiva del principio della collaborazione Stato-Chiesa-confessioni religiose appare di per sé difficilmente arginabile in quanto da catalogare alla voce dei fatti. Ne consegue che risulta tutto sommato più realistico, prospetticamente, interrogarsi sulle sue svariate modalità di traduzione operativa e sugli

del 2021. Come lo stesso A. osserva riportandosi a Corte cost. n. 440 del 1995 e n. 329 del 1997, si può anche dubitare del fatto che di vera e propria ingerenza si tratti, atteso che quella nota verbale è in realtà "priva della sia pur minima attitudine a produrre" quegli effetti di impedimento o ostacolo alle funzioni di governo di uno Stato sovrano che concretano il concetto giuridico di ingerenza.

${ }^{79}$ Per un giudizio fortemente critico, nel metodo ma anche nel merito dell'iniziativa in questione, P. CONSORTI, «Note verbali» e discriminazioni di genere. Un esempio di ingerenza diplomatica, in GenIUS, Rivista di studi giuridici sull'orientamento sessuale e l'identità di genere (www.geniusreview.eu), n. 1/2021.

80 Considerando in maniera più benevola il tenore della richiesta formulata alla Parte italiana, laddove quest'ultima viene sollecitata a "una diversa modulazione del testo" che continui "a garantire il rispetto dei Patti lateranensi".

${ }^{81}$ Non è senza significato il fatto che, nel caso della Santa Sede, si tratta di sovranità affatto peculiare, che è esplicitamente riconosciuta "come attributo inerente alla sua natura, in conformità alla sua tradizione ed alle esigenze della sua missione nel mondo" (art. 2 del Trattato del Laterano), sicché si potrebbe osservare come sia l'universalità della missione che compete alla Santa Sede a legittimarne o persino richiederne (non già l'ingerenza) ma l'intervento su questioni che si ritengano essere pertinenti a tale missione, anche laddove la loro definizione normativa competa in tutto allo Stato. Ciò senza nulla togliere al fatto che, evidentemente, si tratta comunque di un intervento preventivo, il che peraltro lascia ancora fuori dai giochi il meccanismo di cui all'art. 14 dell'Accordo di Villa Madama, atteso che, allo stato, non v'è materia (ovvero controversia sul significato di una o più norme concordatarie) per farvi ricorso.

82 Fermo restando, a tale riguardo, il rischio (evidentemente da evitare decisamente) che l'autorità statale sia chiamata più o meno direttamente (e più o meno chiaramente risponda in senso affermativo) a farsi garante della tenuta interna della Chiesa stessa: cfr. G. CIMBALO, "A chiare lettere - Confronti" •Il papa e la sfida, cit., in particolare p. $18 \mathrm{~s}$. 
impegni, diversificati, che ciascuna di esse comporta in capo alle istituzioni pubbliche a salvaguardia del principio giuridico di laicità e, specificamente, del suo corollario costituito dal principio della distinzione degli ordini ${ }^{83}$.

Da questo punto di vista, vale ribadire che a contare davvero è l'effettivo perseguimento dei fini-valori ordinamentali e la coerente composizione democratico-pluralista degli interessi coinvolti, i quali rientrano, in ultima analisi, nell'alveo della sovranità delle istituzioni pubbliche, dovendosi semmai porre il tema delle modalità di esercizio di questa sovranità e, soprattutto, dei suoi contenuti. Con questa doverosa premessa, la pronta riaffermazione da parte del Presidente del Consiglio Draghi del carattere necessariamente laico dello Stato e della esclusività della potestà legislativa in capo al Parlamento è, per un verso, scontata, per l'altro, meritevole di venire monitorata nel suo seguito effettivo e, quindi, verificata alla prova dei fatti (ovvero del dibattito e, infine, del voto parlamentare).

\section{6 - La nuova fase della ripartenza e il binomio collaborazione- sussidiarietà}

L'emergenza pandemica ha quindi contributo ad accelerare processi già da tempo in itinere, di cui ha reso più evidenti e incombenti pregi e difetti.

In altri termini, le pressioni esercitate dalle sopravvenute priorità politico-istituzionali non sembrano avere prodotto mutamenti sostanziali nella portata dialettica del rapporto tra ordinamento giuridico e interessi sociali religiosi. A fronte della sempre più accentuata propensione estensiva e trasversale di questi ultimi, il primo è continuamente chiamato a ricalibrare gli equilibri faticosamente (ma sempre provvisoriamente) raggiunti nel tentativo di conciliare la sua doverosa autonomizzazione (dal potere religioso) e l'altrettanto doverosa promozione della (eguale) libertà religiosa.

L'esaurirsi delle prime fasi di immediato contenimento della pandemia si accompagna così al ripresentarsi di contrasti e linee di

83 Principio che, posto "al vertice della gerarchia materiale delle fonti, è indisponibile a qualsivoglia normazione bilaterale, come lo stesso art. 1 dell'Accordo di Villa Madama ribadisce": J. PASQUALI CERIOLI, Note di discussione, in J. PASQUALI CERIOLI, S. DOMIANELLO, Aporie e opacità dell'otto per mille: tra interesse pubblico a un pluralismo aperto e interessi specifici alla rigidità del mercato religioso, in Stato, Chiese e pluralismo confessionale, cit., n. 5 del 2020, p. 28. 
frattura insuperati, per certi aspetti fisiologici, che di volta in volta possono cambiare la loro veste formale ma che rimandano a una tensione dialettica di fondo sostanzialmente immutata. Contraddizioni e criticità non del tutto sconosciute, quindi, con le quali occorrerà inevitabilmente confrontarsi anche durante la nuova fase di normalizzazione dell'emergenza e di conseguente ripartenza sociale ed economica del Paese.

In effetti, anche in questo caso il fattore religioso è destinato a svolgere un ruolo di rilievo, quale terreno di emersione, tramite e, allo stesso tempo, elemento connotativo di oscillazioni che coinvolgono lo stesso modo di intendere i valori-fini dell'ordinamento e, per l'appunto, il loro rapporto con le esigenze dell'emergenza.

Indicazioni di tutto rilievo in tale direzione ci provengono proprio dal Piano Nazionale di Ripresa e Resilienza adottato dall'Italia nell'ambito del programma Next Generation EU (NGEU) ${ }^{84}$, la cui governance è stata definita nel recentissimo decreto legge $n .77$ del 2021, convertito con modificazioni dalla legge n. 108 del 2021 e dalle ulteriori disposizioni di quest'ultima, con le quali il legislatore si è premurato di adeguare alle esigenze di questa nuova fase approdi normativi cui era pervenuto di recente.

Cominciando dalle indicazioni del Piano, vale considerare come la rimozione delle diseguaglianze, anche su base religiosa, rientri tra le sue priorità così dette trasversali. È poi interessante registrare le ragioni dichiarate di questo impegno istituzionale, inteso a superare criticità che non rilevano unicamente sul piano individuale ma condizionano il perseguimento di obiettivi di sviluppo e coesione propri della collettività. Esse si condensano nell'affermazione secondo cui

84 Come precisato nella Premessa del documento, il Piano Nazionale di Ripresa e Resilienza (PNRR) consta di "un pacchetto di investimenti e riforme", presentato e finanziato in relazione a uno dei due strumenti del programma europeo Next Generation EU (NGEU, l'altro strumento è costituito dal Pacchetto di Assistenza alla Ripresa per la Coesione e i Territori d'Europa, REACT-EU). Esso si articola in sei Missioni (digitalizzazione, innovazione, competitività, cultura e turismo; rivoluzione verde e transizione ecologica; infrastrutture per una mobilità sostenibile; istruzione e ricerca; inclusione e coesione; salute) e 16 Componenti e "beneficia della stretta interlocuzione avvenuta in questi mesi con il Parlamento e con la Commissione Europea, sulla base del Regolamento RRF". Come si ammette esplicitamente (p. 3), "[p]er 1'Italia il NGEU rappresenta un'opportunità imperdibile di sviluppo, investimenti e riforme. L'Italia deve modernizzare la sua pubblica amministrazione, rafforzare il suo sistema produttivo e intensificare gli sforzi nel contrasto alla povertà, all'esclusione sociale e alle disuguaglianze. Il NGEU può essere l'occasione per riprendere un percorso di crescita economica sostenibile e duraturo rimuovendo gli ostacoli che hanno bloccato la crescita italiana negli ultimi decenni". 
"[1]a persistenza di disuguaglianze di genere, così come l'assenza di pari opportunità a prescindere da provenienza, religione, disabilità, età o orientamento sessuale, non è [...] solo un problema individuale, ma è un ostacolo significativo alla crescita economica" 85 .

Anche in questo caso, non è consentito soffermarsi su profili che, pur rivestendo un'importanza non secondaria, non sono direttamente implicati dal tema di questo contributo. In particolare, non è qui possibile intrattenerci sul significato più profondo (si potrebbe anche dire sui rischi) di quella che può apparire come una (neppure troppo) sottile (ri)funzionalizzazione delle istanze di libertà individuale al perseguimento di obiettivi di coesione e sviluppo economico. Ci si può accontentare di segnalare come il tema più generale che ne è implicato - quello del rapporto tra libertà individuali e interessi generali $\mathrm{o}$, se di preferisce, tra diritti e doveri, considerando tra questi ultimi, anzitutto, il dovere della solidarietà - sia destinato a rimanere a lungo aperto su più fronti operativi (come accade, generando talora una contrapposizione per larga parte impropria, nel caso del così detto green pass ${ }^{86}$ ).

Merita invece evidenziare come, nel contesto di tali dinamiche, le religioni finiscano con l'essere chiamate, nei fatti, a una rilevante opera di affiancamento delle istituzioni pubbliche, mettendo a frutto le proprie capacità inclusive, di mobilitazione e di coesione sociale. E cioè, a seconda dei casi, operando quale potente fattore motivazionale dell'impegno quotidiano dei fedeli, "singoli o associati", in attività che ridondano positivamente a favore della collettività 87 e finanche proponendosi quale

85 Piano Nazionale di Ripresa e Resilienza (PNRR), p. 33.

86 Senza poter entrare nel merito di un dibattito inevitabilmente denso e complesso, ci si può limitare a osservare che si tratta di strumento che comunque appare destinato a conciliare le esigenze di tutela della salute pubblica con ulteriori di rilevanza parimenti generale, ivi comprese quelle di ripartenza dell'economia. Più che opportuna è quindi la preliminare sottolineatura dell'estrema delicatezza delle questioni implicate dall'estensione della operatività del certificato "a molteplici attività interne di carattere produttivo e non". Ne consegue che anche le critiche rivolte a tale estensione sono insuscettibili di venire liquidate "rispedendo al mittente le critiche in nome di una superiore tutela del bene pubblico collettivo o, peggio, dell'incompetenza sul tema sanitario da parte di coloro che hanno redatto o sottoscritto" i documenti che tali critiche hanno portato formalmente all'attenzione delle istituzioni e della politica, del mondo accademico e dell'opinione pubblica: A. POGGI, Green pass, obbligo vaccinale $e$ scelte del Governo, in Federalismi.it Rivista di diritto pubblico italiano, comparato, europeo (www.federalismi.it), editoriale 8 settembre 2021.

87 F. FRENI, Enti ecclesiastici e associazioni etico-religiose in una "new economy" di comunione solidale. Per un'economia dal volto più umano, in Quaderni di diritto e politica ecclesiastica, n. 3/2015, p. 895-921. 
elemento di rafforzamento della persuasività di decisioni politiche che rischierebbero diversamente di risultarne del tutto prive ${ }^{88} \mathrm{o}$ agendo quale collante etico ${ }^{89}$, possibile antidoto alla frammentazione e ponte di dialogo tra le molteplici identità che si agitano nel tessuto sociale.

Evidentemente, è soprattutto nella (talora sfuggente) concretezza delle relazioni economiche che gruppi e confessioni religiose esercitano questo nuovo ruolo, contribuendo significativamente alla rilevazione dei bisogni e degli interessi che si impongono come meritevoli di soddisfacimento e alla predisposizione e messa in opera delle azioni adeguate allo scopo. Ma è altrettanto evidente come ciò rischi seriamente di alimentare ambiguità e zone d'ombra già sperimentate ${ }^{90}$.

Non è da sottovalutare al riguardo l'importanza che lo stesso PNNR assegna all'apporto dei soggetti della società civile e, in particolare, agli enti del Terzo settore precipuamente nel campo delle azioni richieste dalla mission "inclusione e coesione"91. È un richiamo che, evidentemente, non può che coinvolgere gli "enti religiosi civilmente riconosciuti" di cui all'art. 4, terzo comma, del D. Lgs. n. 117 del 2017 (Codice del Terzo settore) e che quindi è destinato a produrre un impatto ecclesiasticistico tutt'altro che marginale.

Sotto questo profilo, la stabilizzazione dell'emergenza e l'avvio della ripresa sembrano poter costituire un'utile occasione di rafforzamento

88 Sulla testimonianza della fede resa dal Romano Pontefice nella sostanziale "accettazione" dei provvedimenti statali di contenimento della pandemia, che peraltro non si presta a una lettura univoca, esemplificativamente, G. CIMBALO, Il papa e la sfida, cit., p. 18.

89 A. FUCCILLO, La Koinè giuridica tra economia, diritto e funzione nomopoietica delle religioni, in Religioni, diritto e regole dell'economia, a cura di G. DAMMACCO, C. VENTRELLA, Cacucci, Bari, 2017, in particolare p. 37 s., ivi ampi riferimenti bibliografici.

90 Sul carattere sintomatico e condizionante della così detta relazione economica, M.C. FOLLIERO, Costituzione e patrimonio ecclesiastico. La relazione economica, in M.C. FOLLIERO, A. VITALE, Diritto ecclesiastico, cit., p. $141 \mathrm{~s}$. Si vedano altresì, con particolare riguardo al meccanismo del così detto otto per mille, J. PASQUALI CERIOLI, S. DOMIANELLO, Aporie e opacità, cit.; C. ELEFANTE, $L^{\prime}$ «otto per mille» tra eguale libertà $e$ dimensione sociale del fattore religioso, Giappichelli, Torino, 2018. Utile altresì confrontare i contributi presenti in Religioni, diritto e regole dell'economia, cit.

91 Cfr. Piano Nazionale di Ripresa e Resilienza (PNRR), in particolare p. 198 s. Qualche ragione di perplessità può forse rinvenirsi nel fatto che il Piano sembra intendere riduttivamente l'ambito materiale di operatività del nuovo Terzo settore, che in effetti (come si evidenzia in P. CONSORTI, L. ROSSI, E. GORI, Diritto del Terzo settore, il Mulino, Bologna, 2021) si colloca ben oltre gli ambiti tradizionalmente riservati allo Stato sociale. 
e rilancio delle relazioni di collaborazione tra istituzioni pubbliche e soggetti religiosi, lungo la direzione tracciata dallo stesso Codice del Terzo settore in tema di amministrazione condivisa.

Ci riferiamo in particolare all'art. 55 del Codice, il quale impone alle

"amministrazioni pubbliche di cui all'art. 1, comma 2, del decreto legislativo 30 marzo 2001, n. 165, nell'esercizio delle proprie funzioni di programmazione e organizzazione a livello territoriale degli interventi e dei servizi nei settori di attività di cui all'articolo $5[\ldots]$ il coinvolgimento attivo degli enti del Terzo settore, attraverso forme di co-programmazione e co-progettazione e accreditamento, poste in essere nel rispetto dei principi della legge 7 agosto 1990, n. 241, nonché delle norme che disciplinano specifici procedimenti ed in particolare di quelle relative alla programmazione sociale di zona"92.

La Corte costituzionale ne ha tratto materia per supportare l'esistenza di

"un nuovo rapporto collaborativo con i soggetti pubblici" in cui "agli ETS, al fine di rendere più efficace l'azione amministrativa nei settori di attività di interesse generale definiti dal CTS, è riconosciuta una specifica attitudine a partecipare insieme ai soggetti pubblici alla realizzazione dell'interesse generale" 93 .

$\mathrm{Si}$ tratterebbe, in altri termini, di "una vera e propria procedimentalizzazione dell'azione sussidiaria", peraltro riservata "in via esclusiva agli enti che rientrano nel perimetro definito dall'art. 4 CTS 94 , ovverosia entro i confini del così detto Terzo settore normativizzato"95.

92 Espliciti riferimenti nello stesso PNNR. Si veda, ad esempio, il paragrafo Investimento 2.2: Piani Urbani Integrati (p. 213 s.).

${ }^{93}$ Così Corte cost. sent. n. 131 del 2020. Si veda altresì Corte cost. sent. n. 255 del 2020.

${ }_{94}$ Per il quale fanno parte del Terzo settore gli enti che rientrano in specifiche forme organizzative tipizzate (le organizzazioni di volontariato, le associazioni di promozione sociale, gli enti filantropici, le società di mutuo soccorso, le reti associative, le imprese sociali e le cooperative sociali) e gli altri enti 'atipici' (le associazioni riconosciute o non riconosciute, le fondazioni e gli altri enti di diritto privato diversi dalle società) che perseguono, "senza scopo di lucro, [...] finalità civiche, solidaristiche e di utilità sociale mediante lo svolgimento, in via esclusiva o principale, di una o più attività di interesse generale in forma di azione volontaria o di erogazione gratuita di denaro, beni o servizi, o di mutualità o di produzione o scambio di beni o servizi", e che risultano "iscritti nel registro unico nazionale del Terzo settore".

${ }_{95} \mathrm{La}$ Corte si premura di evidenziare le ragioni costituzionalmente fondate di questa delimitazione soggettiva, in ciò introducendo un elemento decisivo "per non rendere illegittimamente discriminatoria la previsione del Codice" (E. ROSSI, Il fondamento del Terzo settore è nella Costituzione. Prime osservazioni sulla sentenza n. 131 del 2020 della Corte costituzionale, in Forum di Quaderni Costituzionali, n. 3/2020 (www.forumcostituzionale.it). E 
L'indicazione non è priva di interesse ecclesiasticistico, dal momento che la prospettiva delineata dall'art. 55 del Codice può rappresentare utile occasione per rafforzare e implementare le relazioni tra istituzioni pubbliche e soggetti religiosi, sempre più interessati e legittimati a vedersi inclusi nell'alveo di una collaborazione, la cui connotazione ecclesiasticistica non è sempre immediatamente percepibile ma non per questo è meno incisiva e prospetticamente significativa. Nello specifico, ci troviamo in presenza di una collaborazione che possiamo indicare come 'di diritto comune', di necessità governata, sul piano operativo, dai comuni principi di efficienza e imparzialità della P.A. e finalisticamente orientata al perseguimento dell'interesse generale.

Peraltro, la pienezza di accesso di soggetti e fini religiosi a questi particolari circuiti di specificazione sussidiaria dell'interesse generale ${ }^{96}$,

infatti, ad avviso della Corte, è "agli ETS [che], al fine di rendere più efficace l'azione amministrativa nei settori di attività di interesse generale definiti dal CTS, è riconosciuta una specifica attitudine a partecipare insieme ai soggetti pubblici alla realizzazione dell'interesse generale". Di contro, «[a]gli enti che fuoriescono da tale perimetro legale non possono essere riferibili le medesime forme di coinvolgimento previste dall'art. 55 CTS: esiste una stretta connessione tra i requisiti di qualificazione degli ETS e i contenuti della disciplina del loro coinvolgimento nella funzione pubblica. Infatti, la originale e innovativa (nella sua attuale ampiezza) forma di collaborazione che si instaura mediante gli strumenti delineati dall'art. 55 CTS richiede, negli enti privati che possono prendervi parte, la rigorosa garanzia della comunanza di interessi da perseguire e quindi la effettiva "terzietà" (verificata e assicurata attraverso specifici requisiti giuridici e relativi sistemi di controllo) rispetto al mercato e alle finalità di profitto che lo caratterizzano.». E ancora: si tratta di "un insieme limitato di soggetti giuridici dotati di caratteri specifici" (art. 4), rivolti a "perseguire il bene comune" (art. 1), a svolgere "attività di interesse generale" (art. 5), senza perseguire finalità lucrative soggettive (art. 8), sottoposti a un sistema pubblicistico di registrazione (art. 11) e a rigorosi controlli (articoli da 90 a 97)». Per approfondimenti al riguardo e per la sottolineatura di alcune problematicità insite nelle argomentazioni della Corte, mi permetto di rinviare a G. D'ANGELO, Il modello partecipativo del Codice del Terzo settore e la dimensione ecclesiasticistica del principio di collaborazione. Prime note, in Diritto e religioni, n. 1/2020.

96 In cui peraltro l'ineludibile esigenza di imparzialità e neutralità dei (ovvero, correlativamente di parità di accesso ai) servizi sociali sussidiari può legittimamente comportare significativi oneri di conformazione dell'autonomia e dell'identità confessionale che agiscano (non già sul piano astrattamente soggettivo ma) sul piano del concreto esercizio delle attività e sulla configurazione in senso conforme delle istanze di controllo. Depone in tal senso la stessa delimitazione soggettiva esplicitata dall'art. 55 del Codice, a sua volta legittimata dalla stessa Corte costituzionale. Sotto questo profilo, in particolare, va ribadito il fatto che l'esercizio di determinate attività non è di per sé indice del perseguimento di una finalità di interesse generale, dovendosi piuttosto prestare attenzione alle modalità di svolgimento delle stesse e cioè, in ultima analisi, al loro concreto orientamento finalistico (peraltro ben difficilmente definibile a priori). Ad 
può risultare condizionata dal permanere delle criticità di fondo che caratterizzano sia i meccanismi di riconoscimento civile della soggettività religiosa metaindividuale che le generali modalità di inclusione del fattore religioso all'interno della riforma del Terzo settore.

Nello specifico, l'esclusività del riferimento alla figura soggettiva dell'ETS quale possibile parte del rapporto collaborativo con le istituzioni pubbliche ai sensi dell'art. 55 del Codice rimanda alla locuzione di "enti religiosi civilmente riconosciuti" che, come si è accennato, l'art. 4, terzo comma, dello stesso Codice utilizza per indicare gli enti ecclesiasticireligiosi astrattamente ammessi al regime previsto per gli Enti del Terzo settore (ETS) e agli effetti di esclusione che essa comporta.

A tale proposito, può bastare considerare come, nonostante la maggiore inclusività della nuova formulazione (rispetto a quella fatta propria, in particolare, alle indicazioni del D.lgs.vo n. 460 del 1997 e della normazione di seguito e collegata), l'inclusione degli enti ecclesiasticireligiosi nell'alveo del Terzo settore normativizzato resti parziale, in ragione del permanere della condizione del previo riconoscimento civile di religiosità, che è evidentemente richiesto dalla disposizione in questione laddove si parla, per l'appunto, di enti religiosi civilmente riconosciuti ${ }^{97}$. In

esempio, più concretamente, l'individuazione materiale delle attività di interesse generale non consente di affrontare compiutamente la questione della loro imparzialità. E infatti una volta riconosciuta la qualifica di ETS a un ente religiosamente connotato ci si può trovare dinanzi alla necessità di contenerne la proiezione identitaria sullo svolgimento delle attività di interesse generale svolte. Il che, però, stante l'attuale assetto del Codice, non può che realizzarsi in una fase successiva rispetto a quella della qualificazione soggettiva come ETS e cioè, ad esempio, proprio in sede di coprogrammazione degli interventi.

97 Si veda P. FLORIS, Enti religiosi e riforma del Terzo settore: verso nuove partizioni nella disciplina degli enti religiosi, in Stato, Chiese e pluralismo confessionale, cit., n. 3 del 2018, che evidenzia per l'appunto il contestuale prodursi di "nuove esclusioni". Rileva più in generale la superficialità dell'approccio al tema degli enti ecclesiastici-religiosi da parte del legislatore della riforma del Terzo settore, P. CONSORTI, L'impatto del nuovo Codice del Terzo settore sulla disciplina degli "enti religiosi", in Stato, Chiese e pluralismo confessionale, cit., n. 3 del 2018, cui si rimanda per gli opportuni chiarimenti terminologici e concettuali. Ad avviso dell'A. (in particolare p. 7-8), "la complessità del tema avrebbe dovuto indurre il legislatore a esprimersi con maggiore precisione. Sarebbe stato ad esempio opportuno chiarire se voleva proteggere la finalità spirituale di un ente (quindi la sua religiosità, in senso peraltro lato) oppure la sua appartenenza confessionale. Senza peraltro dimenticare l'esistenza di enti confessionali non religiosi, vale a dire enti istituzionalmente confessionali, e magari riconosciuti come tali anche dallo Stato, che perseguono compiti non religiosi". Ne deriva, in buona sostanza, che «la formula "enti religiosi civilmente riconosciuti" adottata dal Codice [...] appare un improprio impoverimento concettuale, potenzialmente foriero di ulteriore confusione, frutto - se non di ignoranza - di colpevole 
più, tale inclusione si conferma declinata in termini speciali e derogatori, dal momento che, da un lato, l'ente religioso civilmente riconosciuto non è considerato tout court come Ente del Terzo settore (ETS) e, dall'altro, la disciplina per esso predisposta subisce significativi adattamenti e rimodulazioni rispetto a quella prevista per i comuni ETS 98 .

In particolare, si ha anzitutto che la disciplina del Codice si applica (non già all'intero novero delle attività dell'ente religioso ETS ma) limitatamente allo svolgimento delle attività di interesse generale di cui all'art. 5 (nonché, per effetto dell'art. 66 del d.l. n. 108 del 2021, recante Governance del Piano nazionale di ripresa e resilienza e prime misure di rafforzamento delle strutture amministrative e di accelerazione e snellimento delle procedure, convertito in legge e modificato dalla legge n. 108 del 30 luglio 2021, alle eventuali attività diverse di cui al successivo art. $6^{99}$ ) e che a tal

disattenzione».

98 La letteratura in argomento si va vieppiù consistente. Ci si limita qui a ricordare, tra i volumi pubblicati più di più recente, Gli enti ecclesiastici nella riforma del Terzo settore, a cura di P. CAVANA, Giappichelli, Torino, 2021; I. BOLGIANI, Gli effetti della riforma del Terzo settore in materia di «enti religiosi civilmente riconosciuti». Normativa, buone prassi ed esigenze del tessuto sociale, Giappichelli, Torino, 2021.

99 (Disposizioni urgenti in materia di politiche sociali) "Agli enti religiosi civilmente riconosciuti le norme del presente decreto si applicano limitatamente allo svolgimento delle attività di cui all'articolo 5, nonché delle eventuali attività diverse di cui all'art. 6, a condizione che per tali attività adottino un regolamento, in forma di atto pubblico o di scrittura privata autenticata, che, ove non diversamente previsto ed in ogni caso nel rispetto della struttura e della finalità di tali enti, recepisca le norme del presente Codice e sia depositato nel Registro unico nazionale del Terzo Settore. Per lo svolgimento di tali attività deve essere costituito un patrimonio destinato $\mathrm{e}$ devono essere tenute separatamente le scritture contabili di cui all'articolo 13. I beni che compongono il patrimonio destinato sono indicati nel regolamento, anche con atto distinto ad esso allegato. Per le obbligazioni contratte in relazione alle attività di cui agli articoli 5 e 6, gli enti religiosi civilmente riconosciuti rispondono nei limiti del patrimonio destinato. Gli altri creditori dell'ente religioso civilmente riconosciuto non possono far valere alcun diritto sul patrimonio destinato allo svolgimento delle attività di cui ai citati articoli 5 e 6". Giova quindi riprendere il contenuto dell'art. 6 del Codice: "Gli enti del Terzo Settore possono esercitare attività diverse da quelle di cui all'articolo 5, a condizione che l'atto costitutivo o lo statuto lo consentano e siano secondarie e strumentali rispetto alle attività di interesse generale, secondo criteri e limiti definiti con decreto del Ministro del lavoro e delle politiche sociali, di concerto con il Ministro dell'economia e delle finanze, da adottarsi ai sensi dell'art. 17, comma 3, della legge 23 agosto 1988, n. 400, sentita la Cabina di regia di cui all'articolo 97, tenendo conto dell'insieme delle risorse, anche volontarie e gratuite, impiegate in tali attività in rapporto all'insieme delle risorse, anche volontarie e gratuite, impiegate nelle attività di interesse generale". 


\section{fine l'ente stesso sia comunque richiesto di assolvere a particolari} adempimenti e oneri di conformazione ${ }^{100}$.

100 La nuova disposizione estende quindi agli enti religiosi civilmente riconosciuti l'applicazione della disciplina del codice del Terzo settore, oltre che per il ramo dedicato allo svolgimento delle attività di interesse generale di cui all'art. 5 del d.lgs. n. 117 del 2017, anche per la parte di realizzazione di eventuali attività diverse di cui al successivo art. 6. Tale novità normativa (in certo modo anticipata dai commi secondo e terzo del decreto del Ministero del Lavoro e delle Politiche Sociali n. 106 del 2020 sulle procedure di iscrizione al RUNTS) risponde evidentemente a ragioni di sostegno dell'azione sussidiaria degli enti religiosi, nella prospettiva del generale potenziamento delle iniziative di ripresa sociale ed economica che caratterizzano la fuoriuscita dalla prima fase di contenimento del contagio. Prima ancora, essa sembra porre rimedio alla sostanziale irragionevolezza della non menzione originaria della attività di cui all'art. 6 del Codice nell'ambito dell'art. 4, terzo comma. In questo senso, può dirsi che l'adeguamento normativo posto in essere dall'art. 66 del d.l. n. 108 del 2021 risponda a ragioni tecniche e soprattutto di completezza e coerenza interna alla riforma ovverosia alla doverosa presa in carico dell'eventualità - da non escludere a priori (mi permetto di rinviare alle considerazioni espresse in G. D'ANGELO, Attività di culto e Codice del Terzo settore. I "chiarimenti" del Ministero del Lavoro in tema di "attività diverse» (art. 6) e di accesso alle agevolazioni urbanistiche per le attività principali degli ETS (art. 71), in Quaderni di diritto e politica ecclesiastica, n. 3/2019, p. 551 s.) - che anche l'ente religioso possa svolgere attività che pur non direttamente qualificabili come di interesse generale siano caratterizzate da un nesso di connessione/strumentalità rilevante ai sensi dell'art. 6 del Codice. Ciò detto, è altrettanto evidente che la nuova norma è destinata a determinare, per plurimi profili, non secondari problemi interpretativi e di concreta applicazione. Anzitutto, essa inserisce un ulteriore elemento di problematizzazione del già complesso rapporto che intercorre tra "attività di religione e di culto" e attività da considerare "diverse" ai sensi dell'art. 16, lett. b) della legge n. 222/1985 (ovvero delle analoghe disposizioni pattizie), con conseguenze poco chiare quanto alla definizione del concetto stesso di strumentalità rilevante ai sensi della nuova disposizione e in riferimento all'ente religioso civilmente riconosciuto-ETS. In secondo luogo, l'estensione della disciplina di favor normativo (e, inevitabilmente, fiscale) che viene in tal modo a determinarsi appannaggio dell'ente religioso civilmente riconosciuto, amplifica le ricadute negative (in termini di eguaglianza interna alla fenomenologia religiosa) che conseguono alla indicazione soggettiva prevista dall'art. 4, terzo comma, del Codice e di cui dirò immediatamente nel testo. Non ultime, vi sono poi da considerare le difficoltà, teoriche e pratiche, che caratterizzano la fisiologica estensione dell'obbligo di costituzione di patrimonio destinato, che peraltro il citato art. 66 ha provveduto a specificare per più profili, delineando nuovi effetti segregativi e così restituendo qualche incertezza. Segnala in particolare che, nella sua nettezza, l'indicazione legislativa "lascia comunque aperti taluni significativi fronti problematici nell'applicazione di questa figura segregativa", A. PEREGO, Le attività diverse e il patrimonio destinato degli enti religiosi civilmente riconosciuti. Note a margine di recenti integrazioni alle norme sul Terzo settore), in Terzjus. Osservatorio di diritto del Terzo settore, della filantropia e dell'impresa sociale (www.terzjus.it), 31 agosto 2021. Si vedano G. SEPIO, Ets degli enti religiosi, obbligazioni garantite dal patrimonio destinato e L. SIMONELLI, La riforma del Terzo settore, le opere degli enti religiosi e la segregazione del patrimonio destinato, ivi, rispettivamente 17 agosto 2021 e 6 settembre 2021. 
Si pone quindi il problema di dare conto di queste peculiarità disciplinari e, in primo luogo, dell'esclusione che colpisce i soggetti (nella sostanza) religiosi che non rientrino nella nuova formulazione dell'art. 4, terzo comma, del Codice ${ }^{101}$.

Quanto al primo aspetto, si può dire nel complesso e in estrema sintesi che i particolari adempimenti posti in capo all'ente religioso-ETS vadano posti in relazione al carattere generale dell'interesse da perseguire (e, naturalmente, alla scelta di provvedere a una sua tipizzazione normativa), esprimendo più nello specifico la necessità di ricalibrare in ragione di tale doveroso orientamento finalistico le istanze di identità/autonomia dei soggetti che aspirano a vedersi inclusi nel sistema della sussidiarietà.

Discorso non dissimile può essere fatto per riguardo alla qualificazione soggettiva dell'ente religioso-ETS. Qui è lo speciale riconoscimento di personalità giuridica conseguito ai sensi della normativa di derivazione pattizia nonché, stante la nuova formulazione di enti religiosi civilmente riconosciuti, della stessa legge n. 1159 del 1929 ad assolvere alla funzione di asseverazione cui, da altro versante, rispondono gli specifici oneri di conformazione previsti dal Codice. In questo senso, si può dire che il ricorso alla nuova figura dell'ente religioso civilmente riconosciuto costituisca conseguenza tecnico-applicativa di alcune scelte di fondo del legislatore delegante e cioè, da un lato, dell'adozione di un criterio di necessaria prevalenza/esclusività dello svolgimento delle attività di interesse generale (quelle elencate nell'art. 5) e, dall'altro, della mancata considerazione, tra queste ultime, delle attività di religione e di culto, attività il cui esercizio (per l'appunto in via esclusiva o prevalente) è invece per lo più considerato quale requisito essenziale per lo speciale riconoscimento della religiosità civile in capo all'ente ${ }^{102}$.

101 Per approfondimenti e precisazioni al riguardo, mi permetto di rinviare a G. D'ANGELO, Declinazioni giuridiche del fine di religione e di culto. Dalla forma all'interesse, Giappichelli, Torino, 2020, in particolare p. 170 s., 220 s., 285 s.

102 In altri termini, si ha che la qualificazione soggettiva religiosa dell'ente (religioso, per l'appunto) civilmente riconosciuto risponde a criteri analoghi rispetto a quelli sottesi all'attribuzione della qualifica di ETS poiché presuppone la possibilità di una distinzione sufficientemente netta tra attività religioso-cultuali e attività di interesse generale. Si può quindi dire che, in ragione di questi presupposti, il riconoscimento previsto dall'art. 4, terzo comma, del Codice assolva a una funzione di asseverazione della peculiarità tipologica di enti la cui connotazione soggettiva è stata in precedenza dedotta proprio attraverso il riferimento ad attività che non rientrano tra quelle tutelate dal Codice e che quindi, in mancanza di quel riconoscimento, non avrebbero forse titolo a fruire della disciplina di favor ivi prevista. 
Questa circostanza aiuta a collocare le difficoltà derivanti dalla nuova formulazione legislativa all'interno del quadro normativo vigente, di cui in effetti costituiscono logica conseguenza. In altri termini, la delimitazione normativa di cui all'art. 4 , terzo comma, sembra rispondere ad apprezzabili ragioni giuridico-formali ovvero sistematiche. Sul piano sostanziale però esse risultano figlie di una scelta di fondo penalizzante nei riguardi della peculiare connotazione religiosa dell'impegno economico-sociale, connotazione che in larga parte è ritenuta irrilevante.

La considerazione che il Codice riserva agli "enti religiosi civilmente riconosciuti" può così venire riguardata quale conseguenza di questa opzione di fondo e in questo senso risulta sostanzialmente coerente con le esigenze qualificatorio/selettive che ispirano l'art. 5 dello stesso Codice (per quanto temperate dalla previsione del successivo art. 6 e, nello specifico degli enti religiosi, dalla più recente integrazione normativa di cui si è detto). Più precisamente - questo il punto che merita rimarcare - si tratta delle conseguenze che derivano da un sistema di riconoscimento civile della religiosità che concepisce quest'ultima come formula riassuntiva di una relazione fine/attività univoca e immutabile, tendenzialmente impermeabile a ogni ulteriore ordine di valutazioni di tipo funzionale, in termini di meritevolezza di tutela (ovvero di contiguità tra fini religiosi e fini generali ovverosia di effettiva rispondenza all'interesse generale delle attività poste in essere nel perseguimento di una finalità religioso-cultuale). Un sistema di riconoscimento - merita precisarlo - che ha assolto a una funzione meritoria, di perimetrazione della specialità normativa dell'ente ecclesiastico civilmente riconosciuto, che però appare ormai largamente superata dall'andamento delle relazioni socio-economiche e dalla stessa risposta, suggerita dal diritto sovranazionale europeo, di settori significativi dell'ordinamento giuridico.

E infatti, anche nel caso dell'impegno economico sociale, l'attuale presa in carico della dimensione pubblica del fattore religioso risulta solo parziale. Essa non si traduce in un univoco esito di salvaguardia della eguale libertà e neppure consente di apprezzare un sicuro avanzamento in termini di valorizzazione della specificità degli interessi religiosi. Tanto perché, in buona sostanza, la stessa disciplina comune non registra a sufficienza la meritevolezza di tutela del fine religioso-cultuale, assunto in una accezione più ampia e generica di quella normativa attuale ${ }^{103}$.

103 Sull'importanza prospettica di una più compiuta e coerente valorizzazione del fattore religioso nel contesto dei processi evolutivi del sistema della sussidiarietà e, in particolare, del nuovo Welfare sussidiario, non disgiunta dalle cautele intese a impedire il prodursi di ostacoli alla eguale tutela dei diritti e delle libertà fondamentali di credenti e 
A ciò si aggiunga il perpetrarsi della condizione di diseguaglianza (anche) interna alla fenomenologia religiosa che deriva dall'applicazione del principio di bilateralità pattizia e dal trascinamento dei suoi effetti di qualificazione e selezione nel contesto delle forme di collaborazione che si instaurano a livello regionale e locale e che contribuiscono a rendere ancora più profondo lo scarto tra confessioni (e rispettivi enti) dotate di intesa e confessioni prive di intesa.

A questo proposito, non è superfluo osservare che nello snodarsi dell'emergenza pandemica regioni ed enti locali non hanno rinunciato a proporsi quali protagonisti della sperimentazione di soluzioni di collaborazione con i soggetti religiosi innovative, più adeguate alle esigenze dei mutamenti culturali e socio-economici in atto ${ }^{104}$. Allo stesso tempo però non si può escludere, prospetticamente, l'ipotesi che i nuovi spazi della collaborazione ecclesiasticistica possano fungere da ulteriore elemento di tensione per l'unità della Repubblica, infrangendo il limite ragionevole della frammentazione normativa nella disciplina di materie per le quali, invece, l'esigenza (unitaria) di uguaglianza dei cittadini sull'intero territorio nazionale si fa vieppiù forte, si può dire impreteribile.

\section{7 - Riepilogo e rilancio}

non, mi permetto di rinviare al più recente G. D'ANGELO, Nuovo Welfare sussidiario $e$ fattore religioso. Ragioni, limiti, contraddizioni, Giappichelli, Torino, 2021.

104 Valga considerare, esemplificativamente, come tra le misure di rilancio economico connesse all'emergenza pandemica alcune Regioni abbiano da tempo previsto la concessione di contributi straordinari per il potenziamento e/o il rilancio della funzione socioeducativa degli oratori parrocchiali al fine di "conciliare i tempi di lavoro con quelli familiari, agevolando il rientro a lavoro dei genitori" (così il Decreto del dirigente del servizio politiche sociali e sport n. 203 del giugno 2020, emanato in attuazione della Delibera della Giunta regionale Marche n. 743/2020). In maniera sostanzialmente non dissimile, la Regione Campania, intendendo favorire la collaborazione tra regione ed enti e istituzioni che perseguono quale propria missione il contrasto della marginalizzazione sociale e disagio giovanile, alla luce del forte degrado socioeconomico che caratterizza alcuni ambiti territoriali regionali e del suo aggravarsi in conseguenza dell'emergenza sanitaria connesso al Covid-19, ha approvato lo schema del protocollo di intesa con la Conferenza episcopale regionale, avente a oggetto le azioni di contrasto alla marginalizzazione sociale per la valorizzazione del ruolo delle parrocchie nella comunità civile e pastorale (Delibera giunta regionale Campania n. 354 del 09 luglio 2020): C. ELEFANTE, La ridefinizione dello spazio pubblico della religiosità: gli oratori tra dimensione sociale aggregativa ed educazione cristiana, in Spazio pubblico per il fenomeno religioso, a cura di A. FABBRI, Giappichelli, Torino, 2020, p. 194 s. 
Il passaggio dalle prime fasi di contenimento dell'emergenza alla prospettiva della ripartenza sociale ed economica prelude quindi a nuovi spazi di riconoscimento della dimensione pubblica del fattore religioso, investendone tanto i profili individuali che quelli collettivo-istituzionali. Il fattore religioso è destinato così a giocare un ruolo non secondario nel contesto dei processi di definizione e di consolidamento dei nuovi equilibri ordinamentali che andranno a caratterizzare l'auspicata fuoriuscita dalla pandemia.

Ciò significa che le già dense e articolate interrelazioni che il fattore religioso instaura con l'ordinamento giuridico sono destinate a estendersi e a divenire ancora più complesse, impattando problematicamente sui principi cardine del diritto ecclesiastico italiano e sulla normazione di seguito. Gli esiti sono tutt'altro che definibili con certezza a priori, dal momento che un simile scenario può costituire occasione sia per un significativo passo avanti nella direzione della più compiuta integrazione tra fattore religioso e valori-fini ordinamentali che, all'opposto, per un malaugurato regresso, scandito dal presentarsi di vecchie e nuove criticità e contraddizioni.

In particolare, la pregevolezza prospettica del contributo offerto dal fattore religioso alla dinamica dell'attuazione/attualizzazione costituzionale può risultare vanificata, per un verso, dal rischio di un ulteriore sviamento funzionale (o comunque di una non accorta traduzione operativa) delle garanzie dedicate e, per l'altro, dal mancato o non sufficiente contenimento delle mai sopite pretese di egemonizzazione dell'ordine civile, più o meno dirette ed esplicite. Allo stesso tempo, effetti non meno pregiudizievoli di un coerente svolgimento della relazione costruttiva tra fattore religioso e processi di affermazione dei fini-valori ordinamentali possono derivare dal protrarsi di un approccio eccessivamente formalistico, che riconduce alla libertà religiosa le sole forme di manifestazione tradizionali e consolidate della religiosità e in tal modo ne mortifica il potenziale innovativo e di trasformazione sociale.

Peraltro, nello spingere inevitabilmente verso un sensibile rafforzamento delle istanze coesive, le esigenze dell'emergenza rischiano di rappresentare un ostacolo non secondario per la effettiva messa in valore dei più recenti richiami al valore della laicità provenienti dalla stessa giurisprudenza costituzionale ${ }^{105}$. Il diritto dell'emergenza può così

105 Rileva che la giurisprudenza costituzionale ha recentemente prospettato una significativa "estensione garantistica" della laicità "[n]on più [...] descritta solo da un 'pluralismo qualificato', in primis, dall'attenzione alla rappresentanza confessionale degli interessi di fede; ma una laicità aperta al vissuto, volendo de-istituzionalizzato, in cui si 
costituire terreno fertile per il prodursi di nuovi irrigidimenti della dinamica pluralista e per una sottovalutazione (o, all'eccesso opposto, per un fraintendimento) del valore costruttivo della libertà religiosa. In questo senso, si può riconoscere come, pur in forme rinnovate, il tema del rapporto tra la dimensione individuale e la dimensione collettiva e collettivo-istituzionale della libertà religiosa si confermi a tutt'oggi fronte problematico interno (al sottosistema del diritto ecclesiastico) e polo di tensione dialettica esterna (nei confronti dell'ordinamento generale) tra i più complessi, significativi e meritevoli di attenzione.

Con queste premesse, occorre registrare costruttivamente l'obsolescenza degli strumenti di garanzia e di promozione tradizionali e tuttora in uso e di conseguenza propendere per un approccio meno preconcetto e più elastico alla relazione tra interessi generali e interessi religiosi, in cui questi ultimi non siano costretti in astratte e rigorose predefinizioni di campo, affinché l'indeclinabilità della sintesi pubblica proceda di pari passo con la valorizzazione di ogni possibile contributo al progresso materiale e spirituale della società.

\section{8 - Note di discussione: i pregi (prospettici)}

Mi persuade la trama sottesa alle riflessioni che Giuseppe D'Angelo ha proposto alla nostra attenzione nella sua ricca relazione. Il diritto ecclesiastico, da tempo, affronta e cerca di proporre una sintesi, ordinata dal principio supremo di laicità ${ }^{106}$, tra $\mathrm{i}$ poli, tradizionalmente contrapposti, della libertà e dell'autorità, tra i diritti dell'individuo e i poteri delle istituzioni civili e religiose, tra l'uguaglianza e il privilegio. La pandemia ha senz'altro stressato questa incessante ricerca, ma la materia è sembrata disporre, non senza sorpresa per taluno, di qualche solido

esprime la libertà (essa stessa citata priva di aggettivi, financo riferiti alla coscienza) di ciascuno, che ha diritto di manifestarsi al massimo grado senza discriminazioni", J. PASQUALI CERIOLI, Parola, ideologia e sicurezza a novant'anni dalla "legge sui culti ammessi". Dalla "libera" discussione in materia religiosa alla libertà di propaganda, in Diritto e Religioni, Quaderno monografico 1, n. 1-20, p. 222, nonché ID., (Non)conclusioni, cit., p. 183-184, laddove si richiamano le considerazioni di M. TOSCANO, Crocifisso nelle aule scolastiche, cit., p. 898, secondo cui questa formulazione "estende il riferimento alla libertà a quella non religiosa ed eleva il pluralismo da regime di contesto a oggetto immediato della tutela, attirando da ultimo anche il principio di imparzialità tra i contenuti primari del principio".

106 Come ci ricorda G. D'ANGELO, L'utile "fine del monopolio delle scienze ecclesiasticistiche". Prime riflessioni su diritto ecclesiastico e autonomia differenziata delle Regioni ordinarie, in Stato, Chiese e pluralismo confessionale, cit., n. 10 del 2019, p. 19. 
anticorpo dogmatico in grado di combinarsi con le cure del momento e di affrontare un presente e un futuro, per certi versi, inediti.

Ritengo quindi - con il titolo di questo nostro intervento - che i pregi prospettici conseguenti al 'lascito' del contagio da COVID-19 al nostro settore di studi giuridici siano significativi. Il più importante, a mio giudizio, è la ritrovata centralità del principio solidaristico nel governare la composizione tra le istanze di garanzia della libertà religiosa e la chiamata al rispetto di altri interessi apicali concorrenti della collettività ${ }^{107}$. Si tratta di una traiettoria finora poco indagata, con la dovuta attenzione, anche nei nostri studi ${ }^{108}$, benché la tematica, nei suoi aspetti generali, costituisca un architrave del costituzionalismo contemporaneo ${ }^{109}$.

È noto che il principio di solidarietà, fondante l'impianto della Carta ${ }^{110}$ nella sua coessenziale dimensione unitaria, dia vita, addirittura, a un macro-sistema, nel quale la positivizzazione dei correlati doveri111 contiene il ruolo promozionale dell'uguaglianza sostanziale (al servizio del diritto di ciascuno di sviluppare liberamente la propria personalità) entro una prospettiva non isolata, integrata, che colloca l'individuo "nella vita dell'ordinamento e della collettività"112. La funzione non risponde a un postulato ideologico (comunitaristico), ma rappresenta un presupposto che assegna alla situazione soggettiva di doverosità, autonoma rispetto a

107 Interessanti, a questo proposito, le osservazioni di G. MACRÌ, La libertà religiosa alla prova del Covid-19. Asimmetrie giuridiche nello "stato di emergenza" e nuove opportunità pratiche di socialità, in Stato, Chiese e pluralismo confessionale, cit., n. 9 del 2020.

108 Ma non solo, come osserva L. VIOLINI, I doveri inderogabili di solidarietà: alla ricerca di un nuovo linguaggio per la Corte costituzionale, in AA. VV., I doveri costituzionali: la prospettiva del giudice delle leggi, a cura R. BALDUZZI, M. CAVINO, E. GROSSO, J. LUTHER, Giappichelli, Torino, 2007, p. 518 ss.; tra gli studiosi di diritto ecclesiastico che si sono spinti ad affrontare la complessa tematica segnalo F. FRENI, La libertà religiosa tra solidarietà e pluralismo. Analisi e proposte sul modello della laicità "all'italiana", Jovene, Napoli, 2013, e G. CASUSCELLI, Enti ecclesiastici e doveri di solidarietà, in Stato, Chiese e pluralismo confessionale, cit., n. 7 del 2014.

$109 \mathrm{Mi}$ limito a segnalare, per un inquadramento generale nel nuovo millennio, il lavoro di F. GIUFFRÈ, La solidarietà nell'ordinamento costituzionale, Giuffrè, Milano, 2002, e i contributi raccolti nel volume collettaneo a cura di B. PEZZINI e C. SACCHETTO, Il dovere di solidarietà, Giuffrè, Milano, 2005.

110 Come indica la Corte cost. nella centrale sentenza n. 75 del 1992.

111 In argomento, rinvio, per un'indagine monografica recente, a F. POLACCHINI, Doveri costituzionali e principio di solidarietà, Bononia University Press, Bologna, 2016.

112 La bella espressione è di A. APOSTOLI, Il consolidamento della democrazia attraverso la promozione della solidarietà sociale all'interno della comunità, in Costituzionalismo.it, 2016-71, p. 3. 
quella di favore, lo scopo di consentirne espressione effettiva in una relazione di "circolarità"113, ancorché senza vincoli di necessaria corrispondenza o reciprocità 114 .

La solidarietà assolve così il ruolo di circoscrivere il gioco di esercizio delle libertà fondamentali entro un campo teleologicamente ordito sulla responsabilità 115 e sull'apertura a un mutuo riconoscimento della pari dignità 116 , che involge "orizzontalmente" i singoli (e i gruppi) e "verticalmente" i pubblici poteri117. Il fine non è solo scongiurare la prevalenza assoluta di un diritto sull'altro, ma pure impedire, in concreto, che condizioni "politiche, economiche e sociali" di minorità ostacolino la partecipazione di tutti alle dinamiche costruttive delle comunità, nazionali e sovranazionali118, di appartenenza. È questa una ragione centrale per la quale l'oggetto del triplice impegno imposto dall'art. 2 Cost. corrisponde al triplice ambito in cui si articola l'organizzazione del Paese ai sensi dell'art. 3 Cost., a propria volta al centro del compito promozionale di intervento che grava sulla Repubblica (in quanto) democratica ${ }^{119}$.

In quest'ottica, la 'causa' della collaborazione tra Governo e (alcune) confessioni nell'affrontare, malgrado qualche ritrosia ${ }^{120}$, la pandemia sembra afferire al piano di una doverosità solidale matura, rispettosa del dettato costituzionale sotto molteplici profili.

Il primo tocca - appunto - l'inderogabilità dei doveri che grava su ogni soggetto reclami la garanzia dell'esercizio di un diritto inviolabile. Non fa eccezione, per le comunità di fede, la libertà religiosa in forma

113 Così A. RUGGERI, Il principio di solidarietà alla prova del fenomeno migratorio, in Consulta online, 30 ottobre 2017, in particolare p. 448 ss.

114 Come insegna S. ROMANO, Frammenti per un dizionario giuridico, Giuffrè, Milano, 1947, p. 91 ss.

115 Sul punto F. PIZZOLATO, Finalismo dello Stato e sistema dei diritti nella Costituzione italiana, Giuffrè, Milano, 1999.

$116 \mathrm{Si}$ concentra su questo aspetto L. CARLASSARE, Solidarietà: un progetto politico, in Costituzionalismo.it, 2016-71, p. 52 ss.

117 Secondo la fortunata distinzione proposta da S. GALEOTTI, Il valore della solidarietà, in Diritto e società, 1996, p. 10 ss.

118 Sulla quale, di recente (seppure in altro ambito di studi), F. CROCI, Solidarietà tra Stati membri dell'Unione europea e governance economica europea, Giappichelli, Torino, 2020, p. 52 ss.

119 Sul punto A. MORELLI, I principi costituzionali relativi ai doveri inderogabili di solidarietà, in forumcostituzionale.it, 20 aprile 2015, p. 6.

120 Si veda P. CONSORTI, Religion and Virus, in Law, Religion and Covid-19 Emergency, a cura di P. CONSORTI, in DireSom, maggio 2020, in particolare p. 15 ss. 
associata/organizzata, secondo la dogmatica più convincente, anche di matrice convenzionale ${ }^{121}$, che vede, in ultima analisi, nei "diritti e [nel]le libertà altrui" il limite ultimo all'esercizio della libertà di pensiero, coscienza e religione.

Il secondo concerne il corretto inquadramento di suddetta collaborazione nell'alveo del principio supremo di laicità e, in particolare, del corollario essenziale della distinzione degli ordini. L'esperienza dei protocolli sulle "celebrazioni liturgiche e religiose" sottoposti alla firma delle rappresentanze confessionali $\mathrm{ci}$ ha mostrato che i contenuti di impegno delle parti sono stati individuati, correttamente, previa selezione di interessi inquadrati nell'ambito riservato ora delle res temporales (gli standard precauzionali al fine di contenere la diffusione del contagio) e ora dello specifico religioso (l'adattamento al culto, inteso in senso ampio, di siffatte misure di precauzione) ${ }^{122}$.

Il terzo riguarda il condivisibile allontanamento, nell'occasione ${ }^{123}$, del sistema del modello di bilateralità 'dirigista' disegnato dopo il discutibile approdo offerto alla discrezionalità politica dell'Esecutivo dalla criticata sentenza n. 52 del 2016 della Corte costituzionale, che sembra ormai deputato solo a calibrare, secondo la ragion politica, la rigidità del mercato religioso ${ }^{124}$. A quest'ultimo proposito, merita segnalare, a mio avviso, che l'apertura raggiunta in favore di gruppi religiosi non previamente beneficiati dalle leggi "sulla base di intese"125 rispetta il principio pluralista sancito dal primo comma dell'art. 8 Cost., purché aperto a qualunque interlocutore volenteroso, al fine di allontanare i dubbi di casualità nella cernita degli istanti ${ }^{126}$. Ma non solo. L'ampliamento degli interessati sembra anche escludere che le parti abbiano attribuito ai suddetti protocolli natura inter-ordinamentale, tipica delle fonti pattizie (in quanto) al servizio della disciplina dei (meri) "rapporti", tecnicamente intesi ai sensi degli articoli 7, secondo comma, e 8, terzo comma, Cost., ed esposti, ormai, a spinte di politicizzazione in contrasto con l'urgenza di assumere decisioni uniformi ${ }^{127}$.

${ }^{121}$ Rinvio, per tutti, a M. TOSCANO, Il fattore religioso nella Convenzione Europea dei diritti dell'Uomo, ETS, Pisa, 2018.

122 Sul punto, M.L. LO GIACCO, I "Protocolli per la ripresa", cit.

123 Rinvio sul punto a F. ALICINO, Costituzione e religione in Italia, cit., p. 19 ss.

124 In argomento, S. DOMIANELLO, J. PASQUALI CERIOLI, Aporie e opacità, cit.

125 Si veda A. TIRA, Normativa emergenziale, cit.

126 Segnalati da G. CASUSCELLI, Gli "effetti secondari", cit., p. 14.

127 Sul punto A. FERRARI, Covid-19 e libertà religiosa, cit. 
Infatti, simili strumenti di concertazione (più che di contrattazione), quantunque descrittivi di aree di intervento riferibili ad ambiti di reciproca alterità, svolgono i propri effetti all'interno dell'ordine statuale ${ }^{128}$, fugando il rischio di una paventata bilateralità "diffusa"129. Ai protocolli, invero, non pare potersi attribuire autonoma forza di produzione, siccome meri allegati alle fonti, formalmente e sostanzialmente unilaterali, loro richiamanti ${ }^{130}$.

Il maggior pregio che scaturisce dallo stress test della pandemia sul diritto ecclesiastico riposa però, a mio avviso, nell'ampliamento del canone di "reciproca collaborazione", che ritengo abbia acquisito nella nostra materia portata di principio generale ${ }^{131}$. La sua sub-settorialità genetica supera l'alveo di bilateralità nel quale trova diretta espressione normativa, contribuendo a chiarire il significato dell'ambigua formulazione che la scrittura 'politica' dell'art. 1 dell'Accordo di Villa Madama ci mostra.

L'impegno al "pieno rispetto" della distinzione degli ordini non desta, infatti, particolari sforzi interpretativi quale regola che sovraintende le dinamiche dei rapporti Stato-Chiesa contenendole all'interno dei margini del divieto di reciproche ingerenze negli spazi di sovranità esclusivi. Ł̀ la vaghezza del contiguo rimando alla "promozione dell'uomo" e al "bene del Paese" che solleva(va) non poche incertezze interpretative. La formula pare(va) lasciare aperto il campo a dubbi di possibili commistioni tra fini-valori identitari per entrambe le Parti, in ipotesi sovrapponibili perché delimitanti medesime fasce di interessi, ma

${ }^{128} \mathrm{Al}$ quale è ascrivibile la garanzia della salute e della libertà di religione nei suoi aspetti generali (come ho sottolineato in J. PASQUALI CERIOLI, L'indipendenza dello Stato e delle confessioni religiose, cit., in particolare p. 102 ss.); conforme, per la tematica che ci occupa, A. FERRARI, Covid-19 e libertà religiosa, cit.

${ }^{129}$ Che pure, in dottrina, si è ritenuta compatibile con il modello concertativo (F. FRENI, I "nuovi accordi", cit., p. 30 ss.).

130 Sul punto, A. CESARINI, I limiti all'esercizio del culto nell'emergenza sanitaria e la 'responsabile' collaborazione con le confessioni religiose, in Stato, Chiese e pluralismo confessionale, cit., n. 18 del 2020, p. 20-21.

${ }^{131}$ Condivido, al riguardo, il pensiero di A. CESARINI, I limiti all'esercizio del culto, cit., p. 18, il quale osserva come la collaborazione sembri persuadere soprattutto se riferita a soggetti portatori di valori estranei "all'ethos laico della Repubblica", vieppiù se parimenti originari e indipendenti (sul punto, seppure partendo da altro presupposto teorico e con diversa prospettiva applicativa, O. FUMAGALLI CARULLI, Lo Stato italiano e la Chiesa cattolica: indipendenza, sovranità e reciproca collaborazione (a proposito dell'art. 1 Accordo di revisione concordataria), in Stato, Chiese e pluralismo confessionale, cit., $\mathrm{n}$. 3 del 2014, p. 6 ss.). 
in tesi indisponibili alla collaborazione propriamente concordataria in quanto espressivi dell'irriducibile indipendenza tra potere civile e potere religioso.

Simile quadro ermeneutico, a tratti fumoso, si è fatto più chiaro una volta disancorata la "reciproca collaborazione" dal fondo obbligante, nel quale è stata formalmente posta, dei rapporti pattizi, per necessità di sistema allocati negli spazi di disponibilità negoziale - fermi gli ordini comunque distinti - all'accordo delle Parti.

La "collaborazione" tra Stato e Chiesa supera la propria originaria dimensione dispositiva quando si fa esercizio solidale ad ambizione generale, elevandosi a mezzo di adempimento dei doveri inderogabili che gravano anche sull'istituzione ecclesiastica allorché reclami, specularmente, tutela effettiva del diritto inviolabile alla libertà di religione. A questa stregua, la decisività deontica della solidarietà in termini finalistici di concretizzazione 'responsabile' di siffatti doveri ${ }^{132}$ consente all'aggettivo "reciproca", riferito a tale collaborazione, di attribuire un significato più preciso agli obiettivi, cui è diretta, di "promozione dell'uomo" e del "bene del Paese"133.

Secondo questa lettura, infatti, la locuzione, ancipite, rinasce, nel rispetto della specificità del diritto ecclesiastico, come coniugazione ordinata del macro-principio solidarista, non diversamente da quanto accade in altri settori del diritto oggettivo, laddove le situazioni di doverosità trovano, di volta in volta, distinta focalizzazione.

Non più, pertanto, una tensione verso la "promozione dell'uomo" come spinta di pan-negoziazione/contrattazione su ogni aspetto della dimensione individuale e sociale, ma come prova, da parte di Stato e Chiesa (dunque, ciascuno per le competenze riservate al proprio ordine), di "reciproca responsabilità" (ed eventuale rinuncia a beneficio di diritti nell'occasione concorrenti) nell'attendere ai doveri di solidarietà che il "bene del Paese", di volta in volta, reclama.

"Promozione dell'uomo" e "bene del Paese", allora, costituiscono, più precisamente, l'oggetto di un impegno, solennemente affermato, che estende anche alle istituzioni religiose il dovere ${ }^{134}$ comune di preservare

132 Aspetto sul quale mi ero soffermato, ancorché sinteticamente, in J. PASQUALI CERIOLI, Una Proposta di svolta, in AA. VV., La legge che non c'è. Proposta per una legge sulla libertà religiosa in Italia, a cura di R. ZACCARIA, S. DOMIANELLO, A. FERRARI, P. FLORIS, R. MAZZOLA, il Mulino, Bologna, 2019, p. 349.

133 Sul punto, seppure (ovviamente) in diverso contesto, si veda G. CASUSCELLI, Enti ecclesiastici e doveri di solidarietà, cit., p. 17 ss.

134 Sul coinvolgimento delle istituzioni religiose nell'adempimento dei doveri 
responsabilmente l'ordinamento italiano, inter alia, da spinte disgregative, secondo il comando apicale dell'art. 2 Cost. ${ }^{135}$. Non può trattarsi d'altro, pertanto, se non di un principio generale che permea tutto il sistema di relazioni con la Chiesa (e con gli altri soggetti religiosi a carattere originario) e non solo il sub-settore dei loro rapporti pattizi. Nell'emergenza pandemica, la reciproca collaborazione ha affrontato la sfida decisiva di preservare il diritto fondamentale alla salute, anche nel suo valore di interesse della collettività ${ }^{136}$.

\section{9 - (segue) i difetti (potenziali)}

Accanto ai pregi prospettici testé sintetizzati, la pandemia ha lasciato sempre con il titolo di questo nostro intervento - anche difetti potenziali.

Il più significativo, a mio avviso, è lo iato tra religione e cultura, che non persuade alla prova della laicità 'vivente'. È opinione condivisa, in letteratura, che i limiti, diretti e indiretti, alla libertà di religione motivati dall'emergenza sanitaria abbiano interessato la libertà di circolazione (anche) per finalità di culto e l'esercizio di quest'ultimo (esteso alle pratiche di fede) in forma - occasionale o di precetto - collettiva, con restrizioni al diritto di accedere ai luoghi di culto, tuttavia, mai chiusi. Per lungo tempo, invece, l'accesso ai "luoghi di cultura"137 è stato del tutto inibito ${ }^{138}$, con poche e isolate voci di dissenso.

costituzionali (e, in particolare, sulle spinte all'uguaglianza sostanziale e alla partecipazione al progresso spirituale della società), rinvio a G. DALLA TORRE, La "filosofia" di un Concordato, in Quaderni di diritto e politica ecclesiastica, 2004/1, p. 89 ss.

${ }_{135} \mathrm{Si}$ veda, ancora, G. CASUSCELLI, Enti ecclesiastici e doveri di solidarietà, cit., p. 23 ss.

136 Considera la collaborazione tra autorità civili e confessioni religiose in concreta prospettiva di attuazione delle campagne vaccinali M. d'ARIENZO, Vaccini anti-covid e fattore religioso, in Milan Law Review, fasc. 2/2021, in corso di pubblicazione; si veda inoltre, in linea, F. BALSAMO, The loyal collaboration between State and religions at the testing bench of the Covid-19 pandemic. A perspective from Italy, in Law, Religion and Covid-19 Emergency, cit., p. 47 ss.

137 Definiti dall'art. 101 del Codice dei Beni culturali (d.lgs. n. 42 del 2004).

138 In via esemplificativa il d.l. n. 6 del 2020 (convertito in 1. n. 13 del 2020) non ha autorizzato la chiusura degli edifici e dei luoghi di culto, ma dei luoghi di cultura (vedi d.p.c.m. 8 marzo 2020), riaperti con d.p.c.m. 17 maggio 2020 e richiusi con d.p.c.m. 3 novembre 2020, disciplina successivamente confermata, dopo l'introduzione dei 'colori', in zona arancione e in zona rossa; con l'introduzione del 'green pass' (d.l. n. 105 del 2021), l'accesso ai luoghi di cultura è stato inibito senza la certificazione, a differenza di quanto stabilito per gli edifici di culto. 
La disparità è (stata) evidente, senza riposare, a mio giudizio, su sufficienti basi di ragionevolezza e di proporzionalità. La carenza di motivazioni tecnico - giuridiche (non tanto sulla chiusura in sé, ma) sul trattamento deteriore è sembrata risentire di una perdurante visione mercificata della cultura come "prodotto"139, dalla quale, almeno in questa prospettiva, resta ancora estranea, in fin dei conti, la religione nella sua dimensione ideale; la quale, per altro, può giovarsi della forza di rappresentanza esercitata dalle confessioni 'politicamente' come collettori di consenso, attraverso i fideles in quanto cives, e istituzionalmente come ordinamenti originari.

Superati alcuni ostacoli di carattere organizzativo, per la verità non secondari, si sarebbero potute adottare analoghe misure, pure fortemente restrittive, che hanno consentito la permanente apertura delle chiese appunto - ai luoghi di cultura, deputati alla fruizione - è bene ricordarlo di "servizi pubblici essenziali"140.

Ho sottolineato sopra la connessione tra il compito promozionale della Repubblica di garantire le condizioni di eguaglianza sostanziale e lo svolgimento effettivo delle posizioni giuridiche di favore (i diritti) e di necessaria partecipazione solidale (i doveri), secondo un modello circolare e dialogante che garantisce la convivenza, in un contesto democratico, delle spinte pluralistiche al particolarismo con la coesione dell'ordinamento giuridico. Di talché, l'attitudine interventista del sistema non è solo funzionale all'esercizio dei diritti (e delle correlate limitazioni, nella specie, motivate dalla tutela della salute individuale e collettiva), ma anche dei doveri, tra i quali quello di concorrere al "progresso spirituale" della società.

L'ambito interessato da questa situazione di doverosità è notoriamente più ampio di quello (positivo e negativo) di religione, trovando in esso sicura dimora non solo gli apporti di coscienza areligiosi, ma anche le tensioni di ricerca dell'uomo, di natura intima e universale insieme, attraverso il 'mistero' dell'esperienza (attiva e passiva) dell'arte. Essa, infatti, insieme alla scienza, partecipa a quell'unicità di valore sul quale riposa l'essenza stessa della forma di Stato democratica, pluralista e laica, che garantisce agli individui di sviluppare la propria personalità ${ }^{141}$ - come dicevo dianzi - 'liberamente', siccome "libere" infatti,

139 Il riferimento è d'obbligo a M. HORKHEIMER, T. ADORNO, Dialektik der Aufklärung, Fischer, Frankfurt, 2010 (1947).

${ }^{140}$ Ai sensi dell'art. 1, punto 2, della 1. n. 146 del 1990.

${ }^{141}$ Quantomeno secondo una concezione 'ampia', di matrice sistematica in relazione 
in un fecondo gioco di specchi, sono aggettivate in Costituzione proprio l'arte e la scienza medesime (art. 33).

È dunque affidata ai pubblici poteri la cura di consentire a "[o]gni cittadino" secondo "la propria scelta" di libertà, senza distinzioni di credo e "di condizioni personali e sociali", di adempiere quel dovere anche con l'elevazione "spirituale" per il tramite della cultura ${ }^{142}$. In questo senso depone, d'altra parte, il funzionale e sistematico impegno, 'gemello'143, della Repubblica di promuovere - appunto - il suo sviluppo, anch'esso inquadrato dalla Carta tra i principi fondamentali (art. 9) ${ }^{144}$.

Né può valere, a confutazione, che il micro-sistema dal quale è stato desunto il principio supremo di laicità non contempli, tra gli elementi che lo compongono, l'art. 4, l'art. 9 e l'art. 33 Cost. Come ogni principio, infatti, tanto più se al vertice dell'ordinamento siccome espressivo dei suoi valori costituenti, la laicità rompe le rigidità di confine che ne ha (solo) descritto, in origine, il disvelamento, per irradiare poi la sua primaziale capacità nomopoietica in ogni settore, orizzontale e verticale, di interesse.

Sicché, il combinato assiologico del principio supremo con le disposizioni testé richiamate ${ }^{145}$ disegna con più precisione il 'riflesso' che protegge ogni contributo "spirituale" alla formazione della coscienza, anche non necessariamente, o non esclusivamente, di matrice (positiva o

agli altri principi fondamentali della Costituzione (sulla quale F. MERUSI, Sub art. 9, in Commentario della Costituzione, a cura di G. BRANCA, Zanichelli, Bologna-Roma, 1975), opposta a una 'selettiva', che sembra preferita da parte della dottrina. Sul punto, anche per gli opportuni richiami di letteratura, rimando a M. CECCHETTI, Commentario alla Costituzione. Art. 9, in (banca dati aggiornata) Leggi d'Italia, in particolare p. 4.

142 Rinvio, per tutti, alle belle pagine di G. ZAGREBELSKY, Fondata sulla cultura. Arte, scienza e Costituzione, Einaudi, Torino, 2014.

${ }^{143}$ L'indissolubile legame tra l'art. 33 e l'art. 9 Cost. è sottolineato da M. AINIS, M. FIORILLO, L'ordinamento della cultura, Giuffrè, Milano, 2003, p. 79.

144 Di "progresso culturale" ha parlato M. AINIS, Cultura e politica. Il modello costituzionale, Cedam, Padova, 1991, p. 10.

145 Un combinato fecondo, perché compositivo del carattere fondamentale del principio che tutela "l'ambiente [materiale o ideale] culturale" (vedi, ex multis, Corte cost., sentt. n. 378 del 2000 e 256 del 2004); vi è chi ha addirittura ipotizzato il carattere 'supremo' del principio, desumibile quale contenuto essenziale del disposto tracciato dall'art. 9 Cost. (F.S. MARINI, Lo statuto costituzionale dei beni culturali, Giuffrè, Milano, 2002, p. 226, a partire dall'ordinanza n. 26 del 1985 della Corte, in questione di legittimità, in riferimento agli artt. 3, 9, 117 e 128 Cost., della 1. n. 810 del 1929, "nella parte in cui ha dato esecuzione nello Stato all'art. 16 capoverso del Trattato fra Santa Sede e l'Italia, relativamente alla facoltà concessa alla Santa Sede di dare agli immobili, menzionati nel Trattato stesso e negli allegati, l'assetto che creda senza autorizzazione o consensi da parte di autorità governative, provinciali o comunali italiane"). 
negativa) religiosa. Lo conferma l'enunciato più recente del principio, che, a partire dalla sua tradizionale attitudine al servizio della libertà (già calata da decenni in un regime di pluralismo anche "culturale"146), ne sviluppa, coerentemente, la portata garantistica abbracciando un "più ampio pluralismo di valori"147, "a sostegno della massima espansione della libertà di tutti, secondo criteri di imparzialità"148. Ogni diversa lettura, d'altra parte, presterebbe il fianco alla critica di aver riproposto, pur sotto altre spoglie, una concezione 'privilegiata' della libertà di religione, mai del tutto abbandonata nella pratica, seppure da tempo formalmente negletta in letteratura.

Per concludere, potremmo, quindi, senz'altro convenire con l'insegnamento che "non di solo pane vive l'uomo", ma - specificando nemmeno 'di sola religione'. 1989.

146 Secondo la 'storica' formula espressa dalla Corte cost. nella sentenza n. 203 del

147 Così, felicemente, le Sezioni unite civili della Cassazione nella recentissima sentenza n. 24414 del 2021, come opportunamente osservato da M. TOSCANO, Il crocifisso 'accomodato', cit., p. 54.

148 Sono le parole di Corte cost., sent. n. 67 del 2017, riprese nella successiva sent. n. 254 del 2019. Ebbi modo di valutare, in un primo commento, la portata innovativa della rinnovata enunciazione del principio di laicità in J. PASQUALI CERIOLI, Parola, ideologia e sicurezza, cit., p. 222; ha sviluppato l'argomentazione M. TOSCANO, Crocifisso nelle aule scolastiche, cit., p. 898. 